ARTICLE

\title{
Stable, high-performance, dendrite-free, seawater-based aqueous batteries
}

\author{
Huajun Tian', Zhao Li1, Guangxia Feng ${ }^{2}$, Zhenzhong Yang ${ }^{3}$, David Fox ${ }^{1,4}$, Maoyu Wang ${ }^{5}$, Hua Zhou (D) ${ }^{6}$,

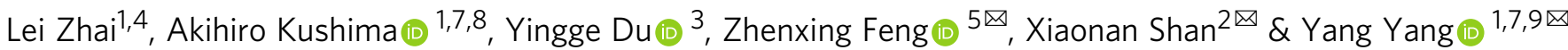

Metal anode instability, including dendrite growth, metal corrosion, and hetero-ions interference, occurring at the electrolyte/electrode interface of aqueous batteries, are among the most critical issues hindering their widespread use in energy storage. Herein, a universal strategy is proposed to overcome the anode instability issues by rationally designing alloyed materials, using $\mathrm{Zn}-\mathrm{M}$ alloys as model systems ( $M=M n$ and other transition metals). An insitu optical visualization coupled with finite element analysis is utilized to mimic actual electrochemical environments analogous to the actual aqueous batteries and analyze the complex electrochemical behaviors. The $\mathrm{Zn}-\mathrm{Mn}$ alloy anodes achieved stability over thousands of cycles even under harsh electrochemical conditions, including testing in seawaterbased aqueous electrolytes and using a high current density of $80 \mathrm{~mA} \mathrm{~cm}^{-2}$. The proposed design strategy and the in-situ visualization protocol for the observation of dendrite growth set up a new milestone in developing durable electrodes for aqueous batteries and beyond.

\footnotetext{
${ }^{1}$ NanoScience Technology Center, University of Central Florida, Orlando, FL 32826, USA. ${ }^{2}$ Electrical and Computer Engineering Department, W306, Engineering Building 2, University of Houston, Houston, TX 77204, USA. ${ }^{3}$ Physical and Computational Sciences Directorate, Pacific Northwest National Laboratory, Richland, WA 99352, USA. ${ }^{4}$ Department of Chemistry, University of Central Florida, Orlando, FL 32826, USA. ${ }^{5}$ School of Chemical, Biological, and Environmental Engineering, Oregon State University, Corvallis, OR 97331, USA. ${ }^{6}$ X-ray Science Division, Argonne National Laboratory, Lemont, IL 60439, USA. ${ }^{7}$ Department of Materials Science and Engineering, University of Central Florida, Orlando, FL 32826, USA. ${ }^{8}$ Advanced Materials Processing and Analysis Center, University of Central Florida, Orlando, FL 32826, USA. ${ }^{9}$ Energy Conversion and Propulsion Cluster, University of Central Florida, Orlando, FL

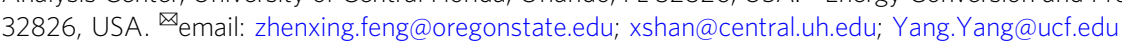


T he strong safety concerns caused by the decomposition of organic electrolytes are challenging non-aqueous lithiumion battery (LIB) communities, posing formidable barriers to reliable electric vehicles (EVs) and personal electronics ${ }^{1}$. Alternatively, emerging metal-anode-based aqueous batteries are attracting increasing attention due to the high-safety of nonflammable electrolytes ${ }^{2-4}$ and environmental benignity ${ }^{5-7}$. More importantly, when coupled with earth-abundant elements (e.g., $\mathrm{O}_{2}$ and $\mathrm{S}$ ) at the cathodes, high-energy-density are possible, leading to cutting-edge technology for the advanced battery systems that exceed the energy density of $500 \mathrm{Wh} \mathrm{kg}^{-1}$ required for the future $\mathrm{EVs}^{8}$. However, inhomogeneous metal plating and electrochemical instability at the liquid-solid (electrolyte/metal anode) interface severely jeopardize the performance and life span of aqueous batteries ${ }^{9-13}$. The inhomogeneous metal plating incurs uncontrollable dendrite growth on the anode surface during charge/discharge cycling, inevitably leading to low Coulombic efficiency (CE), poor cyclability, and even operating failure caused by short-circuit ${ }^{14-16}$. In recent years, various strategies have been suggested to resolve the aforementioned interfacial instability issues of metal anodes in aqueous batteries from the perspectives of materials science and surface chemistry, including structural optimization ${ }^{17}$, surface modification ${ }^{18}$, artificial solid-electrolyte interphases $(\mathrm{SEI})^{19}$, understanding the metal-based battery chemistry, and controlling metal plating 15,20 . Nevertheless, progress in stabilizing metal anodes is still in early infancy, which encourages the aqueous battery communities to explore more efficient and universal strategies for addressing the issues of inhomogeneous metal plating and interfacial instability.

On the other hand, from the perspective of electrolyte chemistry, the solvents and salts used in aqueous electrolytes are among the most important components in aqueous batteries that determine their performance ${ }^{21}$. In practice, deionized (DI) water and high-purity water are commonly used solvents ${ }^{16,21}$ in aqueous batteries to achieve well-controlled battery chemistry by eliminating the interference of hetero-ions (e.g., $\mathrm{Ca}^{2+}, \mathrm{Mg}^{2+}$, $\mathrm{Na}^{+}, \mathrm{SO}_{4}^{-}, \mathrm{Cl}^{-}, \mathrm{NO}_{3}{ }^{-}, \mathrm{F}^{-}$, etc.) on the battery stability ${ }^{21}$. Besides, blended salts have been used in the electrolytes to improve the electrochemical performance of aqueous batteries ${ }^{22,23}$ by tuning the composition of cations and anions in the electrolyte, thereby achieving high ionic conductivity ${ }^{22,24,25}$. However, the complexity of the electrolyte components used in those strategies makes them economically less competitive than current rechargeable battery technologies for industrial-level applications.

Herein, a three-dimensional (3D) alloy anode has been proposed and demonstrated to resolve the interfacial instability issues and improve the electrochemical performance of aqueous batteries using low-cost seawater-based electrolytes. Different from the strategies using surface passivation layers to prevent dendrite growth in non-aqueous lithium electrochemical systems ${ }^{26,27}$, we propose a strategy that will efficiently minimize and suppress the dendrite formation in aqueous systems by controlling: (1) the surface reaction thermodynamics with the favorable diffusion channel of $\mathrm{Zn}$ on the $\mathrm{Zn}_{3} \mathrm{Mn}$ alloy, and (2) the reaction kinetics through the 3D nanostructures on the electrodes, at the same time. The relatively higher binding energy on the surface of the $\mathrm{Zn}_{3} \mathrm{Mn}$ alloy could help to guide and regulate $\mathrm{Zn}$ nucleation and growth and minimize the dendrite formation at the early stage of the deposition. The porous 3D nanostructure will be favorable for controlling the $\mathrm{Zn}^{2+}$ ions diffusion kinetics, further minimizing the dendrite growth throughout the entire deposition process. We designed an optical in-situ visualization protocol that could exactly mimic the actual electrochemical conditions in the aqueous systems. Using this protocol, we observed reversible metal plating and stripping processes within the 3D Zn-Mn anode under different aqueous electrolytes including seawater. Also, theoretical (density functional theory, DFT) and experimental (microscopic and spectroscopic) studies proved that the proposed 3D alloy anode has outstanding interfacial stability achieved by thefavorable diffusion channel of $\mathrm{Zn}$ on the alloy surface. As a proof-of-concept, the proposed $\mathrm{Zn}-\mathrm{Mn}$ alloy anodes were demonstrated to be ultra-stable during the $\mathrm{Zn}$ plating and stripping processes, leading to durable and dendrite-free electrodes for aqueous battery even under a high current density of $80 \mathrm{~mA} \mathrm{~cm}^{-2}$. This work presents a big step towards high-performance, highflexibility, and reliable rechargeable batteries using seawater-based electrolytes. This work also provides a further understanding of aqueous battery chemistry that will advance the use of aqueous batteries in the renewable energy field and beyond.

\section{Results}

Preparation and characterizations of alloy anode. An alloy electrodeposition approach was developed to prepare 3D structured $\mathrm{Zn}-\mathrm{Mn}$ anodes as proposed in this work. This method can be used as a universal strategy for synthesizing various alloy anodes by adjusting the composition of deposition solution, applied deposition current or voltage, and deposition time. In this work, we focused on validating the proposed concept of 3D alloy anode by studying the electrochemical performance of $\mathrm{Zn}-\mathrm{Mn}$ anode. Compared with $\mathrm{Zn}^{2+} / \mathrm{Zn}$, the standard equilibrium potential of $\mathrm{Mn}^{2+} / \mathrm{Mn}$ is much lower (Supplementary Table 1), enabling the $\mathrm{Zn}$ deposition on the surface of $\mathrm{Zn}-\mathrm{Mn}$ alloy unfavorable for $\mathrm{Zn}$ dendrite formation due to the electrostatic shield effect $^{10,28}$. We also demonstrated the potential extension of this alloy electrodeposition strategy by showcasing another anode $\mathrm{Zn}-\mathrm{Cu}$ alloy at the end of this paper. We further suggested other alloys beyond $\mathrm{Zn}-\mathrm{Mn}$ and $\mathrm{Zn}-\mathrm{Cu}$, such as $\mathrm{Zn}-\mathrm{Ni}, \mathrm{Zn}-\mathrm{Co}, \mathrm{Zn}-\mathrm{Fe}$, $\mathrm{Zn}-\mathrm{Mg}$, etc., based on their high corrosion resistance among the typical $\mathrm{Zn}$-based alloys ${ }^{29}$, which will inspire more follow-up works from the battery and materials science communities. The electrodeposition of 3D Zn-Mn alloy was performed in a twoelectrode electrochemical cell by a galvanostatic method (more experimental details in the Methods section). Continuous hydrogen $\left(\mathrm{H}_{2}\right)$ bubbles were observed during the alloy electrodeposition because of water dissociation incurred by the extremely high current density of $0.3 \mathrm{~A} \mathrm{~cm}^{-2}$ used in this work. We varied the electrodeposition time from $10 \mathrm{~min}$ to $40 \mathrm{~min}$ and found that the evolved $\mathrm{H}_{2}$ bubbles served as gaseous templates for the 3D structure formation following the Stranski-Krastanov mechanism (Supplementary Fig. 1 and Supplementary Discussion 1$)^{30}$. The morphologies of the $\mathrm{Zn}-\mathrm{Mn}$ alloy changed from an isolated island-like structure to an interconnected 3D structure with a cauliflower-like surface (Supplementary Fig. 2). Based on the microscopic characterizations, the proposed alloy electrodeposition processes mainly include: (i) co-electrodeposition of various ions $\left(\mathrm{Zn}^{2+}\right.$ and $\left.\mathrm{Mn}^{2+}\right) ;{ }^{31}$ (ii) $\mathrm{H}_{2}$ bubbles evolution at the solid-liquid interface leading to the formation of the 3D structure (Fig. 1a and Supplementary Fig. 3). Meanwhile, the hierarchical pores on the surfaces of the cauliflower-like 3D structures (Supplementary Fig. 4) are beneficial for the facilitated mass transfer during charge/discharge cycling 32,33 . XRD pattern (Fig. 1b) and energy-dispersive X-ray spectroscopy (EDS, Supplementary Fig. 5) elemental mapping confirm the formation of Zn-Mn alloy. The main peaks in the XRD pattern primarily correspond to the phase of P63/mmc(194)-hexagonal $\mathrm{Zn}_{3} \mathrm{Mn}$ (note: in the following discussion $\mathrm{Zn}-\mathrm{Mn}$ alloy and $\mathrm{Zn}_{3} \mathrm{Mn}$ denote the same material). The topography of the Zn-Mn alloy was observed with atomic force microscopy (AFM, Fig. 1c and Supplementary Fig. 6) over a $20 \times 20 \mu \mathrm{m}$ area. The cauliflower-like 3D structures show a hierarchical roughness due to the co-existence of both micro- and 
a

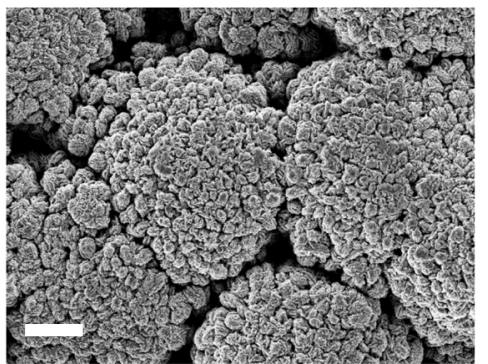

d

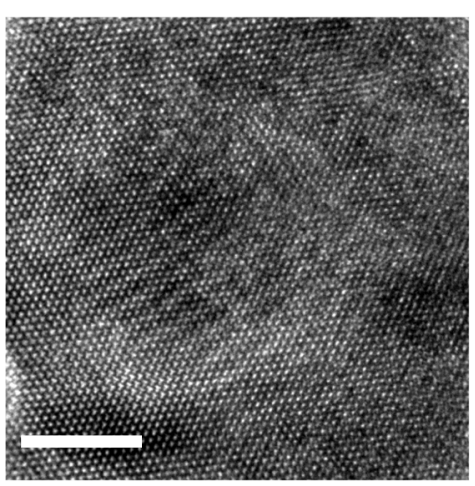

b

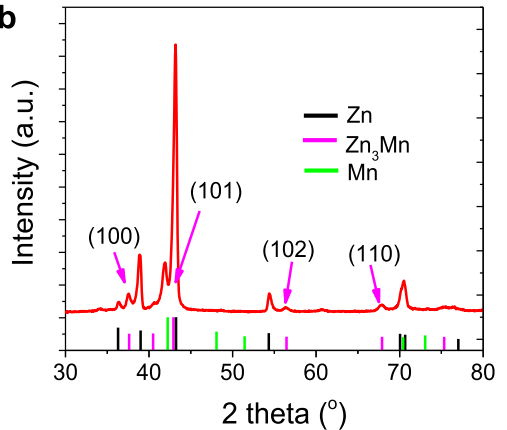

e

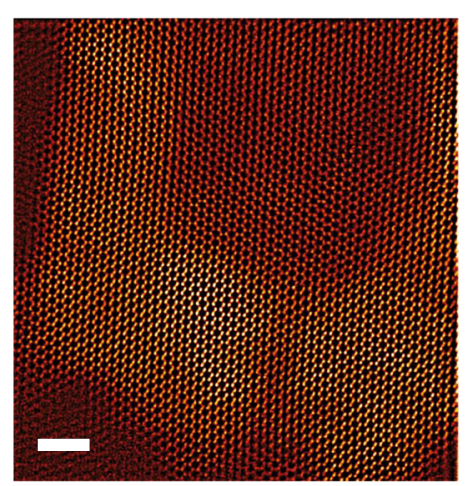

c

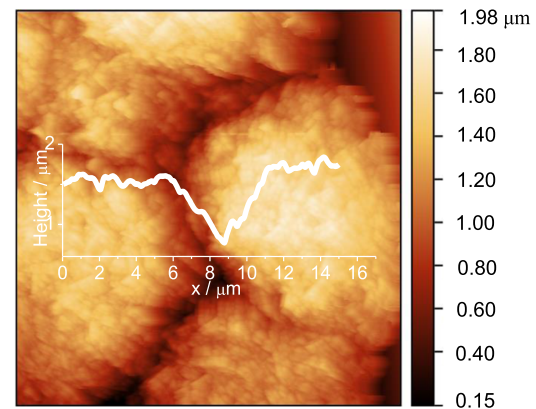

f
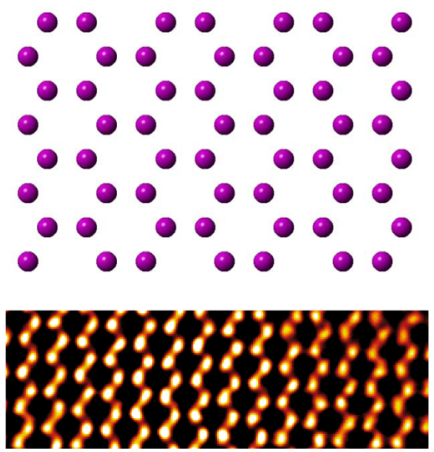

g

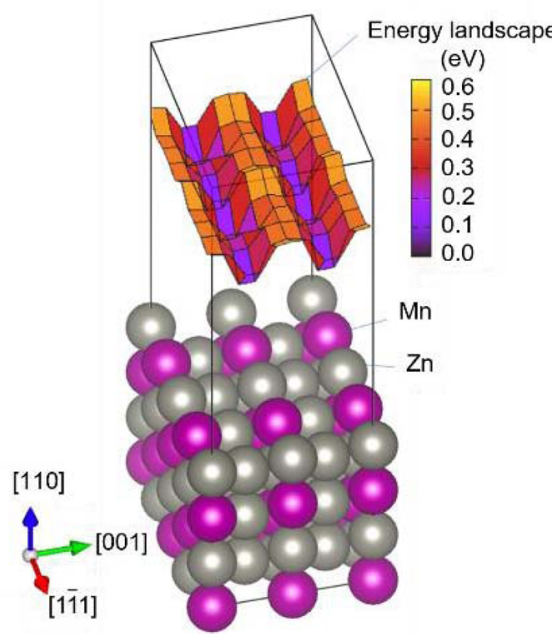

h
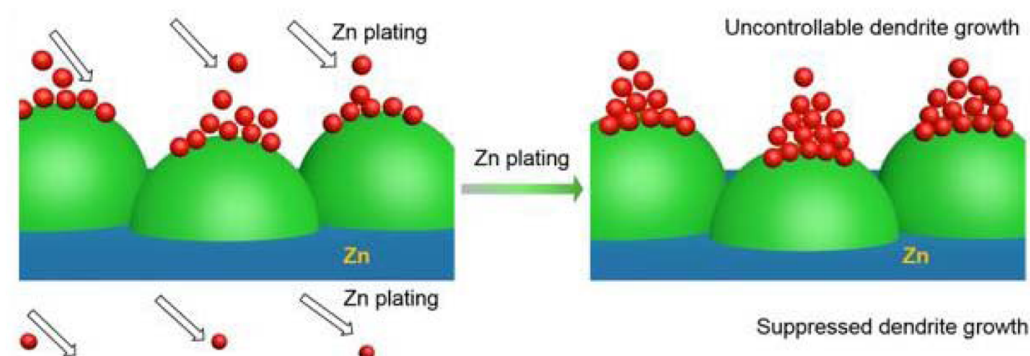

Suppressed dendrite growth
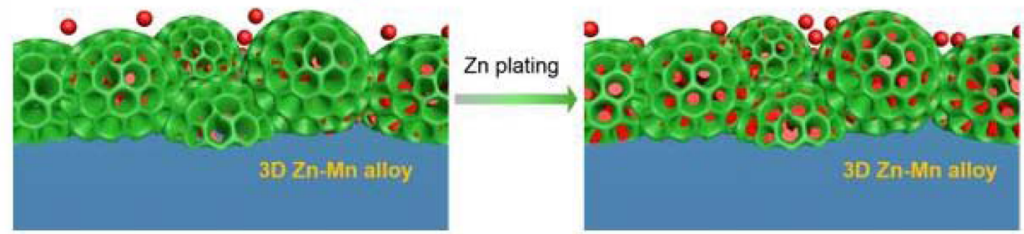

Fig. 1 Preparation and characterizations of the Zn-Mn alloy anode. a SEM image. The scale bar: $10 \mu \mathrm{m}$. b XRD pattern. c AFM image. d HRTEM image of $\mathrm{Zn}_{3} \mathrm{Mn}$ viewed along [001] direction. The scale bar: $10 \mathrm{~nm}$. e, f HAADF-STEM image and the corresponding atomic crystal structure. The scale bars: $2 \mathrm{~nm}$. The purple balls in the crystal structure model represent the co-occupied $\mathrm{Zn} / \mathrm{Mn}$ atoms. $\mathbf{g}$ Atomic structure and the surface ad-atom energy landscape of $\mathrm{Zn}_{3} \mathrm{Mn}$. $\mathbf{h}$ Schematic illustration of $\mathrm{Zn}$ plating processes on $\mathrm{Zn}$ anode (top) and $\mathrm{Zn}-\mathrm{Mn}$ anode (bottom).

nanoscale pores on the surface (Supplementary Fig. 7). After Zn plating, the hierarchical roughness does not show a significant change with the root mean squared (RMS) of $25 \mathrm{~nm}$ and $32 \mathrm{~nm}$ calculated for the $\mathrm{Zn}-\mathrm{Mn}$ anodes before and after $\mathrm{Zn}$ plating, respectively. In contrast, the AFM topographies of the pristine Zn after $\mathrm{Zn}$ plating indicate that the dendrites formation would occur easily even in a range of area capacities from $1.0 \mathrm{mAh} \mathrm{cm}^{-2}$ to $5 \mathrm{mAh} \mathrm{cm}^{-2}$ (Supplementary Fig. 8). The AFM topographies prove that the inhomogeneous dendrite growth is suppressed in the $3 \mathrm{D} \mathrm{Zn}-\mathrm{Mn}$ alloy by the $\mathrm{Zn}$ plating primarily into the hierarchical pores. High-resolution transmission electron microscopy (HRTEM, Fig. 1d) of $\mathrm{Zn}_{3} \mathrm{Mn}$ shows a well-crystallized alloy structure. In addition, atomic resolution high angle annular darkfield (HAADF) scanning transmission electron microscopy
(STEM) images (Fig. 1d-f) show the unique structure of $\mathrm{Zn}_{3} \mathrm{Mn}$, which provides the fast diffusion path for the cations.

Hydrophilic surfaces on metal anodes are essential for homogeneous Zn plating in aqueous electrolytes ${ }^{34}$. The surface wettability of $\mathrm{Zn}_{3} \mathrm{Mn}$ and $\mathrm{Zn}$ anodes with different solvents (DI water and seawater) was characterized by the contact angle (CA) goniometry (Supplementary Figs. 9-11). It is noteworthy that the $3 \mathrm{D} \mathrm{Zn}_{3} \mathrm{Mn}$ anodes with unique 3D structure and nature of alloy possess superhydrophilic characteristics (CA: $0^{\circ}$; Supplementary Discussion 2) compared with the pristine $\mathrm{Zn}$ anode (CA: $103 \pm$ $0.5^{\circ}$ ), enabling the considerably enlarged electrode/electrolyte contact, facilitating the mass transfer, and thus achieving homogeneous $\mathrm{Zn}$ plating. After the calendering process, the surface structure and morphology of the $\mathrm{Zn}-\mathrm{Mn}$ alloy electrode 
remain barely changed even under high pressure of $80 \mathrm{MPa}$, indicating excellent mechanical stability (Supplementary Fig. 12). Even under much higher pressures of $160 \mathrm{MPa}$ and $200 \mathrm{MPa}$, only the top-surface structure of $\mathrm{Zn}-\mathrm{Mn}$ alloy was squeezed. The basic shape of the 3D structured $\mathrm{Zn}-\mathrm{Mn}$ alloy with a large number of voids and trenches remains stable, which provides free space for depositing $\mathrm{Zn}$ metal. Furthermore, density functional theory (DFT) calculations were employed to understand the role of the alloy phase in regulating $\mathrm{Zn}$ nucleation and growth in the plating process. The calculated binding energy of a $\mathrm{Zn}$ atom on the surface of $\mathrm{Zn}_{3} \mathrm{Mn}$ is $1.42 \mathrm{eV}$, a higher value than the $\mathrm{Zn}$ surface $(1.12 \mathrm{eV})$, indicating that the $\mathrm{Zn}_{3} \mathrm{Mn}$ phase could be an ideal matrix to guide the $\mathrm{Zn}$ plating because of a stronger interaction between $\mathrm{Zn}$ and $\mathrm{Zn}_{3} \mathrm{Mn}$. In contrast, the pristine $\mathrm{Zn}$ shows a weaker interaction with $\mathrm{Zn}$ atoms resulting in a greater tendency for dendrite growth. The theoretical understanding of $\mathrm{Zn}$ diffusion on the $\mathrm{Zn}_{3} \mathrm{Mn}$ surface is demonstrated in Fig. 1g, showing the surface structure of $\mathrm{Zn}_{3} \mathrm{Mn}$ and the $\mathrm{Zn}$-ad-atom energy landscape. The energy landscape clearly shows two channels with lower energy and small ripples separating the local minima located at the surface lattice points. The activation barrier for $\mathrm{Zn}$ diffusion is $0.24 \pm 0.025 \mathrm{eV}$, comparable to that of $\mathrm{Li}$ diffusion inside graphite and graphene ${ }^{35-37}$, indicating that $\mathrm{Zn}_{3} \mathrm{Mn}$ could be a promising host for $\mathrm{Zn}$ diffusion. Particularly, the fast $\mathrm{Zn}$ diffusion channel inside the $\mathrm{Zn}-\mathrm{Mn}$ alloy with stronger binding contributes to a homogeneous $\mathrm{Zn}$ coverage on the electrode surface and therefore suppresses dendrite growth (Fig. 1h). In contrast, the $\mathrm{Zn}$ plating/stripping behaviors on the surface of the $\mathrm{Zn}$ anode are inhomogeneous, and subsequently favor the dendrite growth, also known as the "tip effect" 16 .

\section{Alloy anode stability under harsh electrochemical environ-} ments. Traditional metal anodes used in aqueous batteries have poor stability under harsh conditions because of the accelerated corrosion, hetero-ions interference, and unexpected sidereactions. To further examine the electrochemical stability of $\mathrm{Zn}_{3} \mathrm{Mn}$ anode under harsh environments, seawater-based electrolytes consisting of complex compositions (3.5\% saline water containing $\mathrm{Na}^{+}, \mathrm{Mg}^{2+}, \mathrm{Ca}^{2+}, \mathrm{SO}_{4}^{-}, \mathrm{Cl}^{-}$, etc.) were adopted in this work. Another benefit of using seawater-based electrolyte is attributed to its earth abundance and almost free of charge (Supplementary Table 2) 38,39 , providing gigantic economic interest and competitiveness in the increasing energy storage markets. To systematically compare seawater-based electrolytes with conventional DI water-based electrolytes, we prepared nine kinds of aqueous electrolytes using DI water and seawater (Supplementary Fig. 13) as solvents for different metal salts $\left(\mathrm{ZnSO}_{4}, \mathrm{MgSO}_{4}, \mathrm{NaSO}_{4}\right.$, and $\left.\mathrm{MnSO}_{4}\right)$. In general, seawater-based electrolytes have higher $\mathrm{pH}$ levels than DI water-based electrolytes (Fig. 2a), making seawater a viable solvent for the naturally mild aqueous electrolytes. We used a three-electrode electrochemical cell with $\mathrm{Pt}$ as the working electrode and $\mathrm{Zn}_{3} \mathrm{Mn}$ alloy as the counter and reference electrodes to test the reversibility of $\mathrm{Zn}$ plating/stripping behaviors and electrochemical window in an electrolyte composed of $2 \mathrm{M} \mathrm{ZnSO}_{4}$ in seawater (Fig. 2b). The chronocoulometry curves show that the $\mathrm{Zn}$ plating/stripping is highly reversible with a nearly $100 \%$ CE (initial CE: $99.92 \%$ ). A stable and wide electrochemical window up to $2.6 \mathrm{~V}$ was achieved by using a $\mathrm{Zn}_{3} \mathrm{Mn}$ anode in the seawater-based electrolyte without any electrolyte decomposition (Supplementary Fig. 14). The electrochemical stability window of aqueous electrolytes was explored by testing water dissociation potentials (Supplementary Fig. 15a), e.g., hydrogen evolution reaction (HER) and oxygen evolution reaction (OER), in a three-electrode system. The seawater-based electrolyte $\left(2 \mathrm{M} \mathrm{ZnSO}_{4}\right.$ in seawater) has a wider electrochemical window increased from $2.4 \mathrm{~V}$ to $2.6 \mathrm{~V}$ as compared with DI water-based electrolyte $\left(2 \mathrm{M} \mathrm{ZnSO}_{4}\right.$ in DI water). When using seawater as a solvent, the content of free water molecules decreases, which has been proven to be an effective strategy to expand the electrochemical stability window ${ }^{21,40}$. Moreover, the $\mathrm{Zn}_{3} \mathrm{Mn}$ electrode shows a significantly improved anti-corrosion ability in the seawater-based electrolyte as compared to the $\mathrm{Zn}$ electrode (Supplementary Fig. 15b), due to the synergistic effects as reported in the previous reports ${ }^{41}$. On the contrary, a vigorous electrolyte decomposition and much narrower electrochemical windows were detected by using pristine $\mathrm{Zn}$ anode in both DI water-based and seawater-based electrolytes (Supplementary Fig. 16). The CE of Zn plating/stripping processes was further evaluated via $\mathrm{Cu} / / \mathrm{Zn}$ (or $\mathrm{Cu} / / \mathrm{Zn}-\mathrm{Mn}$ ) cells using different aqueous electrolytes. A higher and more stable CE for $\mathrm{Cu} / / \mathrm{Zn}-\mathrm{Mn}$ cells using different aqueous electrolytes was obtained (Supplementary Figs. 17 and 18). For the cycling performance of $\mathrm{CE}$, the $\mathrm{Zn}-\mathrm{Mn}$ alloy appears to have an average CE above $99.6 \%$ over 2500 cycles at a current density of $10 \mathrm{~mA} \mathrm{~cm}^{-2}$ (Fig. 2c), demonstrating the long-term durability of $\mathrm{Zn}_{3} \mathrm{Mn}$ anode in the seawater-based electrolyte. Furthermore, electrochemical impedance spectra (EIS) of $\mathrm{Zn} / / \mathrm{Zn}$ and $\mathrm{Zn}-\mathrm{Mn} / / \mathrm{Zn}-\mathrm{Mn}$ symmetric cells were examined to understand the charge transfer kinetics in different electrolytes. In seawater-based electrolyte, a remarkably reduced charge transfer resistance was achieved with a Zn-Mn//Zn-Mn symmetric cell (Supplementary Fig. 19a), which was much lower than that of $\mathrm{Zn} / / \mathrm{Zn}$ symmetric cell, indicating the facilitated reaction kinetics of $\mathrm{Zn}-\mathrm{Mn}$ alloy. Similarly, the improved reaction kinetics was observed in the $\mathrm{Zn}-\mathrm{Mn}$ alloy symmetric cells using DI water-based electrolytes (2 M $\mathrm{ZnSO}_{4}$ in DI water, Supplementary Fig. 19b) compared with pristine $\mathrm{Zn}$. The nucleation and plateau overpotentials indicate the formation and growth thermodynamics of critical $\mathrm{Zn}$ atoms/ clusters in the plating process ${ }^{42,43}$. The nucleation and plateau overpotentials (27 mV and $19 \mathrm{mV}$, respectively) for the $\mathrm{Zn}-\mathrm{Mn}$ alloy are much lower than those of pristine $\mathrm{Zn}$ anode $(47 \mathrm{mV}$ and $30 \mathrm{mV}$, respectively), further confirming the regulated $\mathrm{Zn}$ plating dynamics for $\mathrm{Zn}-\mathrm{Mn}$ alloy anode (Supplementary Fig. 19c). Moreover, the outstanding stability of $\mathrm{Zn}-\mathrm{Mn}$ anode was further proved by galvanostatic cycling in the symmetric $\mathrm{Zn}-\mathrm{Mn} / / \mathrm{Zn}-\mathrm{Mn}$ cell under an extremely high current density of $80 \mathrm{~mA} \mathrm{~cm}^{-2}$, showing ultra-stable plating/stripping behaviors for over 1900 cycles. Whereas, the short-circuit of the symmetric $\mathrm{Zn} / / \mathrm{Zn}$ cell was observed only after 80 cycles within $<30 \mathrm{~h}$ (Fig. $2 \mathrm{~d}$ and Supplementary Fig. 20). The achieved great improvements in the electrochemical stability of metal anode under harsh environments validate our concept of using a $\mathrm{Zn}-\mathrm{Mn}$ alloy for durable aqueous batteries. To further confirm the significance of $\mathrm{Zn}_{3} \mathrm{Mn}$ in the stabilized electrochemical performance, we prepared a $3 \mathrm{D}$ Zn@Zn anode (Zn foil coated with 3D Zn particles, Supplementary Fig. 21) as a control sample for electrochemical tests. The $\mathrm{Zn}$ plating/stripping profiles and cycling performance of symmetric 3D Zn@Zn cell (Supplementary Fig. 22) exhibit a large overpotential and failure caused by the dendrite growth and the corresponding internal short-circuit within $<100$ cycles at a low current density of $5 \mathrm{~mA} \mathrm{~cm}^{-2}$ and $<250 \mathrm{~h}$ at a high current density of $80 \mathrm{~mA} \mathrm{~cm}^{-2}$. Ex-situ SEM observations (Supplementary Fig. 23) were performed to diagnose the $\mathrm{Zn}$ plating processes under different current densities from $1 \mathrm{~mA} \mathrm{~cm}^{-2}$ to $80 \mathrm{~mA}$ $\mathrm{cm}^{-2}$. The dendrites were observed from the surface of pristine $\mathrm{Zn}$ anode, while a smooth surface without dendrite growth was achieved on the 3D Zn-Mn alloy anode even under harsh conditions such as high current densities up to $80 \mathrm{~mA} \mathrm{~cm}^{-2}$. The demonstrated homogenous $\mathrm{Zn}$ plating double confirmed the favorable binding energy of $\mathrm{Zn}$ atoms and the fast $\mathrm{Zn}$ diffusion channel in the Zn-Mn alloy as suggested by the DFT calculations. 

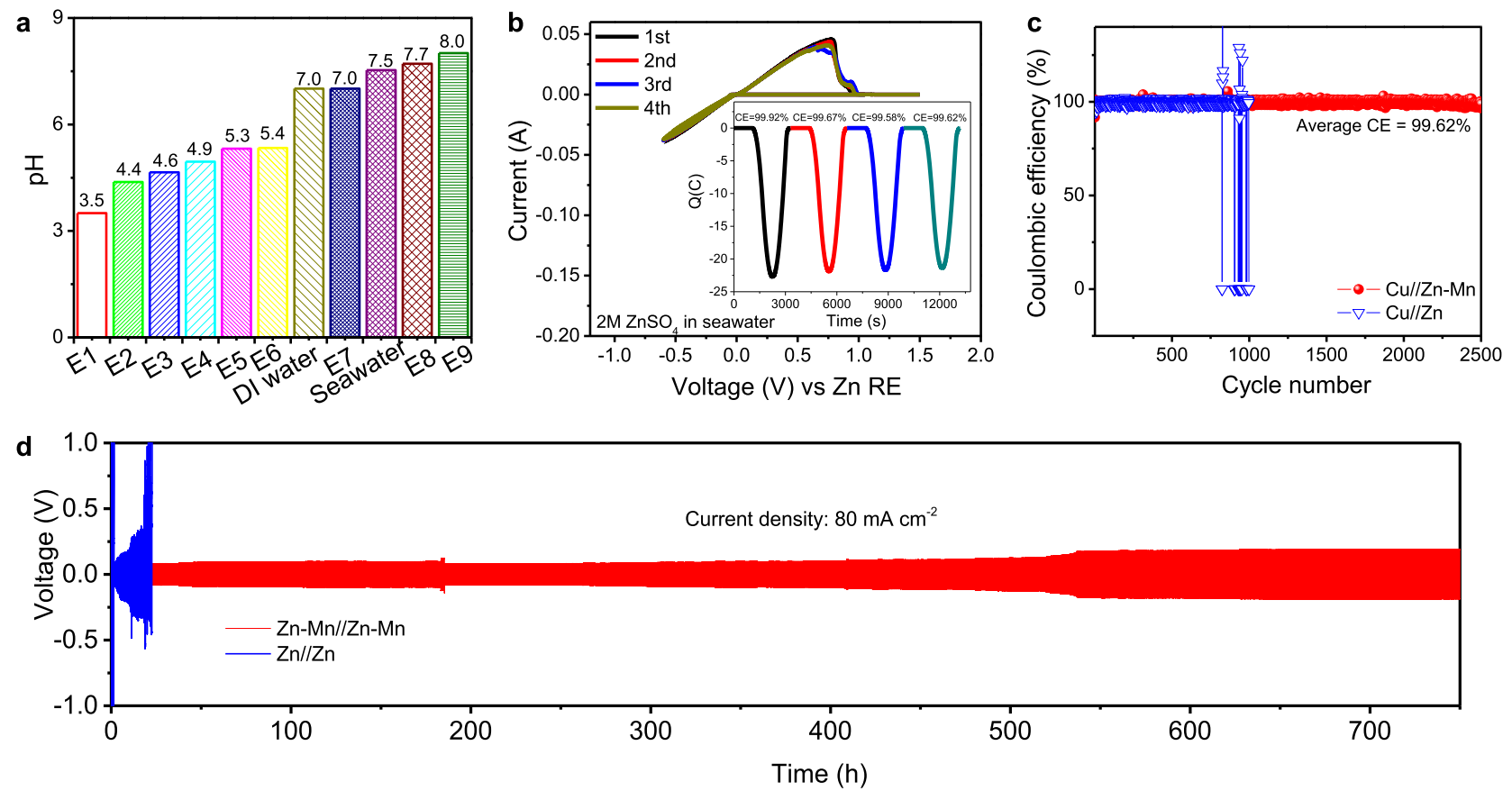

e

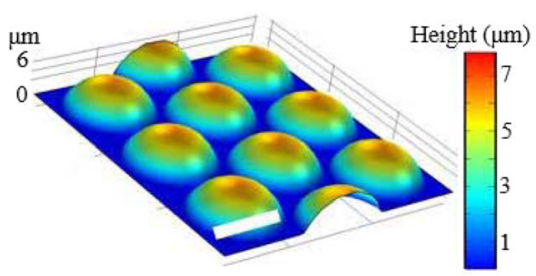

f

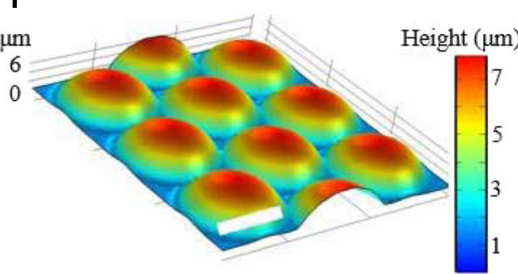

g

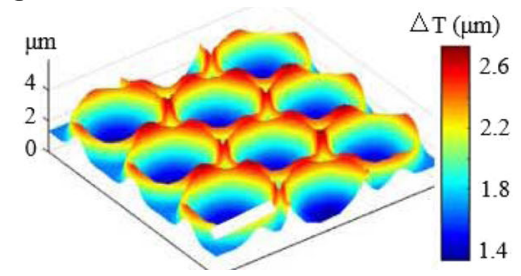

Fig. $\mathbf{2}$ Electrochemical performance and Zn plating/stripping behaviors of $\mathbf{Z n - M n}$ alloy in the aqueous electrolytes. a $\mathrm{pH}$ values of different electrolytes prepared using DI water and seawater as solvents. b Cyclic voltammetry curves of seawater-based electrolytes. Scan rate: $1 \mathrm{mV} \mathrm{s} \mathrm{s}^{-1}$. Working electrode: Pt. Reference and counter electrodes: $\mathrm{Zn}-\mathrm{Mn}$ alloy. $\mathbf{c}$ Long-term galvanostatic cycling performance of $\mathrm{Cu} / / \mathrm{Zn}$ and $\mathrm{Cu} / / \mathrm{Zn}-\mathrm{Mn}$ cells at a current density of $10 \mathrm{~mA} \mathrm{~cm}^{-2}$. d Long-term galvanostatic cycling performance of symmetric $\mathrm{Zn}-\mathrm{Mn}$ and pristine $\mathrm{Zn}$ cells at a current density of $80 \mathrm{~mA} \mathrm{~cm}{ }^{-2}$ (areal capacity: $16 \mathrm{mAh} \mathrm{cm}^{-2}$; Electrolyte: $2 \mathrm{M} \mathrm{ZnSO}_{4}$ in seawater). 3D COMSOL simulation: e Morphology of 3D Zn-Mn alloy in 3D COMSOL model before Zn plating. f Morphology of 3D Zn-Mn alloy after $50 \mathrm{~s}$ of Zn plating. $\mathbf{g}$ Thickness change after $50 \mathrm{~s}$ of Zn plating on the Zn-Mn alloy surface. Scale bars in e-g: $20 \mu \mathrm{m}$.

In-situ visualization of $\mathrm{Zn}$ plating/stripping processes. The $\mathrm{Zn}$ plating and stripping processes in the aqueous batteries were insitu visualized via a specially designed optical protocol (Fig. 3a). We imaged and compared the $\mathrm{Zn}$ plating and stripping processes on $\mathrm{Zn}-\mathrm{Mn}$ alloy and pristine $\mathrm{Zn}$ electrodes under different current densities of $5-80 \mathrm{~mA} \mathrm{~cm}^{-2}$ in DI water and seawater-based aqueous electrolytes. Since the proposed $\mathrm{Zn}$ batteries were operated in $2 \mathrm{M} \mathrm{ZnSO}_{4}$ salt-based aqueous electrolytes, the refractive index mismatch between the air and electrolyte could cause severe distortion and blur the image due to the optical aberration. To minimize this effect, a $\times 20$ water immersion objective was employed. We also constructed 2D and 3D finite element analysis models of electrochemical cells using COMSOL multiphysics (see Supplementary Discussion 3-6) and simulated the plating profile and thickness change on the Zn-Mn alloy. Concretely, Fig. 2e-g, Supplementary Fig. 24, and Supplementary Movie 1 illustrate the $\mathrm{Zn}$ plating process over the entire electrode surface at a current density of $80 \mathrm{~mA} \mathrm{~cm}^{-2}$. The results clearly show that initially, the trenches between the $\mathrm{Zn}-\mathrm{Mn}$ particles filled up rapidly compared to the protruding areas in the early stage. After the initial stage, as the plating proceeded the surface became smoother and the deposition rate in the trenches decreased and resembled deposition in other regions (Supplementary Fig. 25). This process resulted in a uniform electrode surface, which was consistent with the ex-situ SEM characterizations (Supplementary Fig. 23).
For the unique in-situ visualization (Fig. 3a), the objective, top, and bottom electrodes were all immersed in the electrolyte. Since the visible light cannot penetrate through the thick $\mathrm{Zn}$ electrodes, we extended the bottom substrate and imaged the morphology changes by the reflected light intensity on the extended area. Note that the observation area did not directly face the top electrode, which could decrease the electric field and the current density in the area and cause the non-uniform electric field distribution. To minimize this effect, the observation region was chosen as close as possible to the projection of the top electrode. The distance from the edge of the top electrode's projection to the center of the observation area was $200-400 \mu \mathrm{m}$ which was significantly smaller than the separation of the electrodes $(\sim 2 \mathrm{~mm})$, and the current densities in the observation area were similar to those inside the area of the electrodes. Comparing with other imaging techniques that have been utilized to study the metal deposition process, our in-situ optical system provide the direct top view that will clearly illustrate the deposition dynamics at different locations and is easy to use comparing with $\mathrm{X}$ ray imaging which requires the synchrotron beamline ${ }^{44}$. To verify our assumption, a COMSOL model was developed to simulate the current density distribution across the bottom electrode (Supplementary Fig. 26). The current density at the observation area was at $95 \%$ of the maximum values between two electrodes, and this result further verified that the observation area can reflect the changes inside the battery electrodes. 

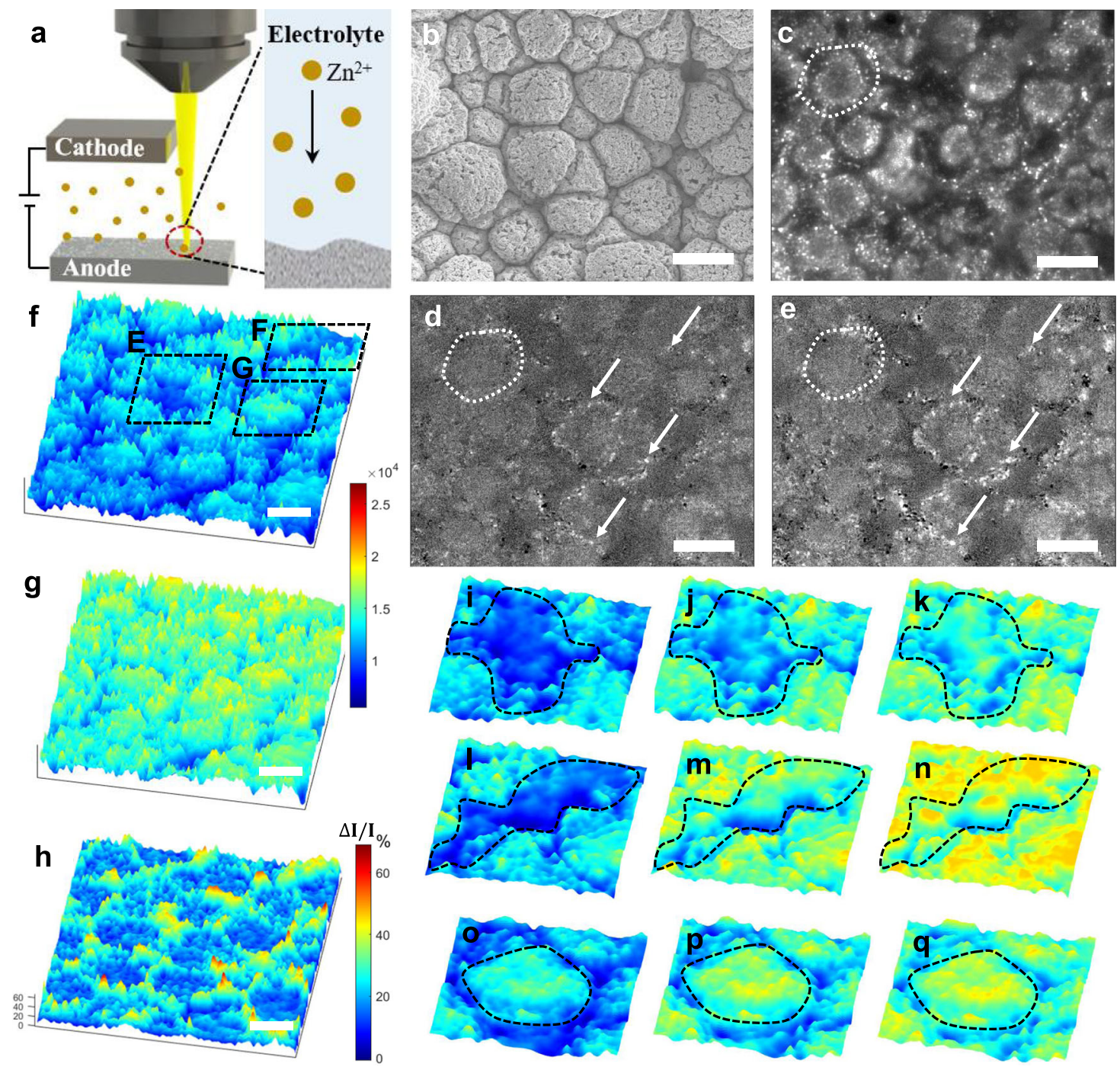

Fig. $3 \mathbf{Z n}$ plating dynamics on 3D Zn-Mn alloy imaged by in-situ optical microscope. a Schematic illustration of the experimental setup. $\mathbf{b}$ SEM image of $3 \mathrm{D} \mathrm{Zn-Mn}$ alloy. c-e The early stage of $\mathrm{Zn}$ plating. Images were taken with a $\times 20$ water immersion objective at 25 frames per second, and the experiment was performed at a current density of $80 \mathrm{~mA} \mathrm{~cm}-2$. c shows the 3D $\mathrm{Zn}-\mathrm{Mn}$ alloy before the experiment. $\mathbf{d}$, e show the differential images at $10 \mathrm{~s}$ and $30 \mathrm{~s}$, respectively, after the start of the experiment. $\mathbf{f}-\mathbf{h} \mathrm{Zn}$ plating on 3D Zn-Mn alloy. The experiment was performed at a current density of $80 \mathrm{~mA} \mathrm{~cm}^{-2}$ for 320 s. $\mathbf{f}, \mathbf{g}$ are the images of $3 D \mathrm{Zn}-\mathrm{Mn}$ alloy before and after Zn plating. $\mathbf{h}$ was calculated by $(\mathbf{g}-\mathbf{f}) / \mathbf{f}=(\Delta l / I)$. $\mathbf{i}-\mathbf{q}$ Evolution of $Z n$ plating on the $3 D$ Zn-Mn alloy. $\mathbf{i}-\mathbf{q}$ are from the three different regions of interest labeled in $\mathbf{f}$, where $\mathbf{i}-\mathbf{k}, \mathbf{I}-\mathbf{n}$, and $\mathbf{o}-\mathbf{q}$ correspond to regions $\mathbf{E}$, $\mathbf{F}$, and $\mathbf{G}$ in $\mathbf{f}$, respectively. The images were taken at $0 \mathrm{~s}(\mathbf{i}, \mathbf{I}, \mathbf{0}), 160 \mathrm{~s}(\mathbf{j}, \mathbf{m}, \mathbf{p})$, and $320 \mathrm{~s}(\mathbf{k}, \mathbf{n}, \mathbf{q})$. The black dashed lines in (i-q) circle out the trench regions (i-n) and the protruding regions (o-q). Scale bars: $10 \mu \mathrm{m}$.

The corresponding SEM and optical images of the 3D Zn-Mn alloy are shown in Fig. 3b, c, respectively. The optical image clearly shows the 3D structures of the $\mathrm{Zn}-\mathrm{Mn}$ alloy with hierarchical pores on the surface. The contrast of the optical image originated from the morphologies and variations in reflectance at different locations. The brighter areas represent material protruding from the surface and high reflectivity, and the darker areas correspond to the trenches and low reflectivity. The shapes and sizes of the 3D structures match very well with those in the SEM images, demonstrating the feasibility of using optical microscopy to study the dynamic process of electrode reactions. To understand the $\mathrm{Zn}$ plating process on the $3 \mathrm{D} \mathrm{Zn}-\mathrm{Mn}$ alloy, a constant current was applied through the electrodes while the optical images were obtained at a certain framerate. The experimental conditions used in the in-situ optical microscopy study were identical to those in the $\mathrm{Zn}$ battery test. The entire $\mathrm{Zn}$ plating process was recorded, and the optical signal reflected the morphological changes during the charging and discharging processes. The spatial resolution in the optical imaging system could not resolve the initial nucleation sites that are smaller than the diffraction limit, however, it allows us to image and measure the entire $\mathrm{Zn}$ deposition process. This information provides critical evidence that we have utilized the morphology of $3 \mathrm{D} \mathrm{Zn-}$ $\mathrm{Mn}$ alloy to control the reaction kinetics and minimize the dendrite formation.

The pristine $\mathrm{Zn}$ anode was studied first using the in-situ optical microscope (Supplementary Fig. 27a). The $\mathrm{Zn}$ dendrites nucleated on the electrode surface after $60 \mathrm{~s}$ of plating and continued to grow through the entire process (Supplementary Fig. 27b, c and Supplementary Movie 2). The results showed that the $\mathrm{Zn}$ plating on the pristine $\mathrm{Zn}$ surface was inhomogeneous, leading to both vertical and lateral growth of dendrites at a certain location (bottom right in Supplementary Fig. 27). To completely understand why the dendrite growth can be suppressed on the surface of this $\mathrm{Zn}-\mathrm{Mn}$ alloy, we carefully studied the $\mathrm{Zn}$ plating dynamics using the in-situ optical microscopy and COMSOL 
simulation. In addition to the outstanding interfacial stability achieved by the favorable diffusion channel of $\mathrm{Zn}$ on the alloy surface, we found two additional reasons that are responsible for the suppressed dendrite growth.

First, in the early stage of deposition, the nano-voids embedded in the 3D $\mathrm{Zn}-\mathrm{Mn}$ alloy structure helped to control the nucleation sites, leading to the random distribution of nucleation sites. Such a structure allows $\mathrm{Zn}$ to deposit easily inside the nano-voids. We found that $\mathrm{Zn}$ plating on the 3D Zn-Mn alloy showed completely different dynamics. In the early stage of $\mathrm{Zn}$ plating on the $3 \mathrm{D} \mathrm{Zn}$ $\mathrm{Mn}$ alloy, the $\mathrm{Zn}$ was mostly deposited inside the 3D structure with hierarchical pores (white dashed regions in Fig. 3c). Figure 3d, e and Supplementary Movie 3 show the differential optical images after $10 \mathrm{~s}$ (Fig. 3d) and $30 \mathrm{~s}$ (Fig. 3e) of $\mathrm{Zn}$ plating at a current density of $80 \mathrm{~mA} \mathrm{~cm}^{-2}$ on the 3D Zn-Mn alloy. Besides, bright spots corresponding to big nucleation sites (marked by white arrows in Fig. 3c) were observed in the trenches of the $3 \mathrm{D}$ structure. These phenomena were caused by the enhanced electric field and the high current density in the nano-voids of the $3 \mathrm{D} \mathrm{Zn-}$ Mn alloy. To verify this hypothesis, a 2D COMSOL model was established to simulate the plating rate and the current density inside and around the nano-void (Supplementary Fig. 28), and the results showed that the $\mathrm{Zn}$ plating rate inside the nanostructure was much faster than that outside.

Secondly, the trenches in the 3D Zn-Mn alloy structures grew faster initially and formed a uniform electrode surface after plating. After the initial nucleation process, $\mathrm{Zn}$ started to deposit over the entire surface. However, the deposition rate varied with location: $\mathrm{Zn}$ deposited much faster in the trench compared with the deposition on the original structures (i.e., protrusions). Figure $3 \mathrm{f}$ shows the initial profile of $3 \mathrm{D} \mathrm{Zn}-\mathrm{Mn}$ alloy before $\mathrm{Zn}$ plating. After a long deposition time $(320 \mathrm{~s}$ under a current density of $80 \mathrm{~mA} \mathrm{~cm}^{-2}$ ), the surface became smoother (Fig. $3 \mathrm{~g}$ and Supplementary Movie 4). To further illustrate this effect, we chose three regions of interest (regions E, F, and G in Fig. 3f), and plotted their changes over time (Fig. $3 \mathrm{i}-\mathrm{q}$ ). The regions marked by the dashed black lines in Fig. 3i-n indicate the trenches on the electrode. These images at different time points (Fig. 3i-n) clearly show that the trenches were filled up quickly, and the final surface became much smoother. Furthermore, protruding regions (original structures), circled by the black dashed line in Fig. $30-\mathrm{q}$ also grew during the $\mathrm{Zn}$ plating process at a relatively slower rate. The percent intensity change over the entire surface is demonstrated in Fig. $3 \mathrm{~h}$. The changes in the trench were much bigger $(40-60 \%)$ than that of the original structures $(20 \%)$. This phenomenon was due to the uneven distribution of the electric field and the current density of the $3 \mathrm{D}$ alloy structure. Note that the color map represents the image intensity, and the bigger intensity corresponds to the higher structure altitude. We have also obtained 3D morphology using our in-situ optical microscope by taking pictures at a different focus plane of entire 3D structures and reconstruct the 3D morphology (Supplementary Fig. 29). The results further verify our conclusion that the deposition in the trench will be much faster than that on the protruding region which minimized the dendrite formation. Supplementary Movie 5-8 illustrate the $\mathrm{Zn}$ plating and the corresponding stripping processes on the same electrode (see Supplementary Discussion 7). We have also quantified the amount of $\mathrm{Zn}$ deposited onto the 3D $\mathrm{Zn}-\mathrm{Mn}$ alloy electrode with no obvious dendrites formation. Supplementary Movie 9-13 shows that the $\mathrm{Zn}$ can be continuously deposited onto the substrate for $>8200 \mathrm{~s}$ with $80 \mathrm{~mA} \mathrm{~cm}^{-2}$ without dendrites, and further demonstrates the superior performance of 3D $\mathrm{Zn}-\mathrm{Mn}$ alloy substrate.

COMSOL models in 2D (Supplementary Fig. 30 and Supplementary Movie 14) and 3D were built to further understand the $\mathrm{Zn}$ plating processes over the $3 \mathrm{D} \mathrm{Zn}-\mathrm{Mn}$ structure as mentioned above. The half-spheres were used to mimic the 3D $\mathrm{Zn}-\mathrm{Mn}$ alloy structure (Fig. 2e and Supplementary Fig. 24). The trenches on the 3D $\mathrm{Zn}-\mathrm{Mn}$ alloy were filled in much faster than the protrude regions (Fig. 2e, f) and became smooth during the plating process. The deposition thickness changed much faster in the trenches (Fig. 2g) which perfectly reproduced the experimental results (Fig. 2e-g vs Fig. 3f-h). During the stripping process, the deposited $\mathrm{Zn}$ was removed and the original 3D surface almost completely recovered (Supplementary Fig. 31). This observation directly proves the absolute reversibility of the plating/stripping process by using $\mathrm{Zn}-\mathrm{Mn}$ alloy, which has never been achieved by other metal anodes. Furthermore, in-situ optical microscopy was used to study the $\mathrm{Zn}$ plating in other aqueous electrolytes to further prove the stability of $\mathrm{Zn}-\mathrm{Mn}$ alloy: (1) $2 \mathrm{M}$ $\mathrm{ZnSO}_{4}$ in seawater; (2) $2 \mathrm{M} \mathrm{ZnSO}_{4}$ and $0.1 \mathrm{M} \mathrm{MnSO}_{4}$ in seawater; and (3) $2 \mathrm{M} \mathrm{ZnSO}_{4}$ and $0.1 \mathrm{M} \mathrm{MnSO}_{4}$ in DI water. No obvious difference was observed (Supplementary Movie 15-17 for electrolyte (1), (2), and (3), respectively), confirming the dendrite-free and ultra-stable nature of 3D $\mathrm{Zn}-\mathrm{Mn}$ alloy anode for aqueous batteries. Pristine $\mathrm{Zn}$ was also tested with seawaterbased electrolyte (electrolyte 2) to compare with the 3D Zn-Mn alloy anode (Supplementary Movie 18 and 19). The movies show that the pristine $\mathrm{Zn}$ has a much faster dendrite formation rate. In addition, $\mathrm{Zn}$ deposited unevenly leading to quickly formed dendrites on the electrode surface, which further demonstrated the advantages of 3D $\mathrm{Zn}-\mathrm{Mn}$ alloy over pristine $\mathrm{Zn}$ metal anode for aqueous batteries.

Dendrite suppression strategy: simultaneous control of thermodynamics and reaction kinetics for $Z n$ plating. In recent years, the study of cathodes for aqueous $\mathrm{Zn}$-air and $\mathrm{Zn}$-ion batteries (ZABs and ZIBs) has been at the forefront of aqueous battery research ${ }^{45-47}$. Different strategies have been suggested and demonstrated to improve the interfacial stabilities. However, the critical issues of $\mathrm{Zn}$ metal anodes, such as dendrite growth, surface passivation and corrosion, etc., have been insufficiently addressed and continue to significantly challenge the development of high-performance and fully-rechargeable aqueous $\mathrm{Zn}$ batteries 48

In this paper, we have proposed and demonstrated a strategy that will efficiently minimize and suppress the dendrite formation by controlling: (1) the surface reaction thermodynamics with the favorable diffusion channel of $\mathrm{Zn}$ on the $\mathrm{Zn}_{3} \mathrm{Mn}$ alloy, and (2) the reaction kinetics through the $3 \mathrm{D}$ nanostructures on the electrodes, at the same time. The relatively higher binding energy on the surface of $\mathrm{Zn}_{3} \mathrm{Mn}$ alloy indicates that the alloy phase is an ideal matrix to guide and regulate $\mathrm{Zn}$ nucleation and growth and minimize the dendrite formation at the early stage of the deposition. On the other hand, the porous 3D nanostructure will help to control the $\mathrm{Zn}^{2+}$ ions diffusion kinetics, and further minimize the dendrite formation throughout the entire deposition process. The combination of both $\mathrm{Zn}_{3} \mathrm{Mn}$ alloy and $3 \mathrm{D}$ nanostructure provides the 3D $\mathrm{Zn}-\mathrm{Mn}$ alloy electrode the superior performance on dendrite suppression and corrosion prevention.

A series of experiments have been conducted to demonstrate that the high-performance dendrite-free $3 \mathrm{D} \mathrm{Zn}-\mathrm{Mn}$ alloy is the result of both (1) $\mathrm{Zn}_{3} \mathrm{Mn}$ alloy which will control the surface reaction thermodynamics; and (2) the $3 \mathrm{D}$ nanostructure will control the 3D reaction kinetics. We have fabricated the flat $\mathrm{Zn}_{3} \mathrm{Mn}$ electrode by mechanically pressing the $3 \mathrm{D} \mathrm{Zn}-\mathrm{Mn}$ alloy and imaged the $\mathrm{Zn}$ deposition with our in-situ optical microscope. The results show that the $\mathrm{Zn}$ deposition happens on the flat $\mathrm{Zn}-\mathrm{Mn}$ alloy area immediately and there is no obvious 
dendrite formed within $900 \mathrm{~s}$ at $80 \mathrm{~mA} \mathrm{~cm}^{-2}$ (Supplementary Fig. 32 and Supplementary Movie 20). Comparing with the pristine $\mathrm{Zn}$ electrode, which starts to show dendrite formation after just $100 \mathrm{~s}$ (Supplementary Fig. 27 and Supplementary Movie 2), the flat $\mathrm{Zn}-\mathrm{Mn}$ alloy shows the good capability to control the surface reaction and suppress the dendrite formation. On the other hand, the 3D Zn-Mn alloy does not show obvious dendrite formation after $8200 \mathrm{~s}$ of $\mathrm{Zn}$ deposition (Supplementary Fig. 33 and Supplementary Movie 9-13) under the same experimental conditions. Besides, we have fabricated a $3 \mathrm{D} \mathrm{Zn}$ substrate without $\mathrm{Mn}$, and the result shows improved performance comparing with the pristine $\mathrm{Zn}$ surface but still outperformed by the 3D Zn-Mn alloy (Supplementary Fig. 22). These results indicate that by coupling with the $\mathrm{Zn}-\mathrm{Mn}$ alloy composition, the $3 \mathrm{D}$ nanostructures help to control the deposition kinetics and further minimized the dendrite growth.

Electrochemical performance of $\mathrm{Zn}-\mathrm{Mn}$ anode in aqueous $\mathrm{Zn}$ batteries. To demonstrate the practical performance of the $\mathrm{Zn}$ $\mathrm{Mn}$ anode in aqueous batteries, we assembled ZABs using commercial Pt/C@ $\mathrm{RuO}_{2}$ as the cathode and $\mathrm{Zn}-\mathrm{Mn}$ alloy as the anode (Supplementary Fig. 34a). A control battery was assembled using the pristine $\mathrm{Zn}$ as the anode for a comparison. The ZABs using $\mathrm{Zn}-\mathrm{Mn}$ anodes showed excellent charge/discharge cycling stability for over $6000 \mathrm{~min}$ test without degradation at a current density of $10 \mathrm{~mA} \mathrm{~cm}^{-2}$. In contrast, the $\mathrm{ZABs}$ using $\mathrm{Zn}$ anodes failed quickly after $2760 \mathrm{~min}$ test with a huge hysteresis (Fig. 4a). The galvanostatic discharge capacities of ZABs using different anodes were recorded (Fig. $4 \mathrm{~b}$ and Supplementary Fig. 34b). Note that ZABs $\left(\mathrm{Zn}_{3} \mathrm{Mn}\right)$ and $\mathrm{ZABs}(\mathrm{Zn})$ are used to represent the batteries using $\mathrm{Zn}_{3} \mathrm{Mn}$ and $\mathrm{Zn}$ anodes, respectively, to reduce the wordy description. At a high current density of $30 \mathrm{~mA} \mathrm{~cm}^{-2}$, the $\mathrm{ZABs}\left(\mathrm{Zn}_{3} \mathrm{Mn}\right)$ delivered an extremely high discharge capacity of $816.3 \mathrm{mAh}_{\mathrm{Zn}}{ }^{-1}$ corresponding to an energy density of $798.3 \mathrm{Wh} \mathrm{kg}_{\mathrm{Zn}}{ }^{-1}$, higher than those of ZABs (Zn; $784 \mathrm{mAh}$ $\mathrm{g}_{\mathrm{Zn}}{ }^{-1}$ and $657{\mathrm{Wh} \mathrm{kg}_{\mathrm{Zn}}}^{-1}$ ) and superior to the recent benchmarking $Z A B s^{49-51}$. The significantly improved performance of the $\mathrm{ZABs}\left(\mathrm{Zn}_{3} \mathrm{Mn}\right)$ is ascribed to the sufficiently exposed active areas in the hierarchically porous $3 \mathrm{D}$ architectures via this surface/interface engineering ${ }^{52}$. To further demonstrate the outstanding $\mathrm{ZABs}\left(\mathrm{Zn}_{3} \mathrm{Mn}\right)$ performance, we used our most recently developed materials composed of the co-incorporated platinum $(\mathrm{Pt})$ and fluorine $(\mathrm{F})$ in the PtCo nanosheets as a cathode to replace commercial Pt/C@ $\mathrm{RuO}_{2}{ }^{53}$. As a proof-of-concept, a high peak power density of $196 \mathrm{~mW} \mathrm{~cm}^{-2}$ (Fig. 4c) was achieved by $\mathrm{ZABs}\left(\mathrm{Zn}_{3} \mathrm{Mn}\right)$, which was much higher than that of ZABs $(\mathrm{Zn})$ $\left(130 \mathrm{~mW} \mathrm{~cm}^{-2}\right)$. Besides, the $\mathrm{Zn}-\mathrm{Mn}$ alloy is also mechanically robust and can be used for flexible ZABs. The flexible ZABs $\left(\mathrm{Zn}_{3} \mathrm{Mn}\right)$ in tandem cells exhibited nearly doubled voltages under different current densities. Under repeated twisting, the flexible tandem $\mathrm{ZABs}\left(\mathrm{Zn}_{3} \mathrm{Mn}\right)$ retained a stable voltage and sustained an electric fan without any malfunction (Fig. $4 \mathrm{~d}$ and Supplementary Movie 21). At the same time, the voltages of tandem ZABs $\left(\mathrm{Zn}_{3} \mathrm{Mn}\right)$ at high current densities were quite stable, confirming the outstanding performance for the $\mathrm{Zn}-\mathrm{Mn}$ anode (Supplementary Fig. 35). Moreover, we assembled ZIBs full cells using $\mathrm{MnO}_{2}$ cathodes, $\mathrm{Zn}-\mathrm{Mn}$ alloy anodes, and seawater-based electrolyte $\left(2 \mathrm{M} \mathrm{ZnSO}_{4}\right.$ and $0.1 \mathrm{M} \mathrm{MnSO}_{4}$ in seawater) to evaluate the electrochemical performance of $\mathrm{Zn}-\mathrm{Mn}$ anode for aqueous $\mathrm{ZIBs}$ (Supplementary Fig. 36). The addition of $\mathrm{Mn}^{2+}$ in the electrolytes would improve the reversibility, greatly enhance the utilization of $\mathrm{MnO}_{2}$ active material, and suppress the dissolution of $\mathrm{MnO}_{2}$ in aqueous $\mathrm{Zn} / / \mathrm{MnO}_{2}$ batteries ${ }^{2,54}$. The $\mathrm{ZIBs}\left(\mathrm{Zn}_{3} \mathrm{Mn}\right)$ using seawater-based electrolytes presented a higher capacity $(373.2$ $\mathrm{mAh} \mathrm{g}^{-1}$, Fig. $4 \mathrm{e}$ ) at $0.5 \mathrm{C}$ and higher discharge voltage plateaus than that of ZIBs $(\mathrm{Zn})\left(262.5 \mathrm{mAh}^{-1}\right)$, confirming a more efficient charge transfer dynamics based on the $\mathrm{Zn}-\mathrm{Mn}$ anode.

We also investigated the anti-interference property of $\mathrm{Zn}-\mathrm{Mn}$ anode against hetero-ions such as $\mathrm{Na}^{+}$and $\mathrm{Mg}^{2+}$ in the seawaterbased electrolyte. As a control experiment, the $\mathrm{ZIBs}\left(\mathrm{Zn}_{3} \mathrm{Mn}\right)$ using $\mathrm{Na}^{+}$-containing electrolyte $\left(2 \mathrm{M} \mathrm{Na}_{2} \mathrm{SO}_{4}\right.$ in seawater $)$ showed a noticeable capacity of $30 \mathrm{mAh} \mathrm{g}^{-1}$, indicating a considerable storage capability in the ZIBs $\left(\mathrm{Zn}_{3} \mathrm{Mn}\right.$; Supplementary Fig. 37). Besides, we used a $\mathrm{Mg}^{2+}$-containing electrolyte ( $2 \mathrm{M}$ $\mathrm{MgSO}_{4}$ in seawater) to test the $\mathrm{Mg}^{2+}$ anti-interference property in the ZIBs $\left(\mathrm{Zn}_{3} \mathrm{Mn}\right)$. A distinct intercalation behavior was observed in the ZIBs $\left(\mathrm{Zn}_{3} \mathrm{Mn}\right)$ with a high initial capacity of 110 mAh $g^{-1}$ (Supplementary Figs. 38 and 39a, b) compared with the pristine $\mathrm{Zn}$ anode (Supplementary Fig. 40). We also investigate the impact of hetero-ions $\left(\mathrm{Na}^{+}\right.$and $\left.\mathrm{Mg}^{2+}\right)$ on the electrochemical performance of $\mathrm{Zn}-\mathrm{Mn}$ alloy in the symmetric $\mathrm{Zn}-\mathrm{Mn} / /$ Zn-Mn cells (Supplementary Fig. 39c, d). And the antiinterference property of $\mathrm{Zn}-\mathrm{Mn}$ anode against the other heteroions, including $\mathrm{Ca}^{2+}$ and $\mathrm{Cl}^{-}$, has also been investigated as shown in Supplementary Fig. 41, confirming the insignificant effect of hetero-ions (e.g., $\mathrm{Ca}^{2+}$ and $\mathrm{Cl}^{-}$) on the electrochemical performance of $\mathrm{Zn}-\mathrm{Mn}$ alloy. The results also confirmed the highly anti-interference behaviors of the $\mathrm{Zn}-\mathrm{Mn}$ anode. Furthermore, the $\mathrm{ZIBs}\left(\mathrm{Zn}_{3} \mathrm{Mn}\right)$ using seawater-based electrolyte exhibited a stable capacity of $300 \mathrm{mAh} \mathrm{g}^{-1}$ at $1 \mathrm{C}$, whereas the ZIBs (Zn) delivered a much lower capacity of $130 \mathrm{mAh} \mathrm{g-1}$ (Fig. 4f), demonstrating the superior electrochemical performance of ZIBs based on Zn-Mn anode in the seawater-based electrolyte. In particular, the self-discharge test of $\mathrm{ZIBs}\left(\mathrm{Zn}_{3} \mathrm{Mn}\right)$ using the seawater-based electrolyte showed no drop in open-circuit voltage for $120 \mathrm{~h}$ (Supplementary Fig. 42). Furthermore, at a high rate of $4 \mathrm{C}$ (Fig. 4g), the ZIBs (Zn) failed quickly after 368 cycles due to dendrite growth and short-circuit. In sharp contrast, the ZIBs $\left(\mathrm{Zn}_{3} \mathrm{Mn}\right)$ could keep a very stable performance over 2000 cycles without any dendrite growth and short-circuit (Supplementary Fig. 43), suggesting outstanding stability under harsh conditions far surpassing those of other benchmarking $\mathrm{Zn}$ anodes (Supplementary Table 3). The slow activation of the $\mathrm{Zn} / / \mathrm{MnO}_{2}$ batteries as shown in Fig. $4 \mathrm{~g}$ could be caused by: (i) the diffusing paths of $\mathrm{Zn}^{2+}$ ion are gradually constructed due to the continuous infiltration of electrolytes after cycling; (ii) during the electrode activation process, more reactive sites could be exposed and the ionically conductive network of $\mathrm{Zn}^{2+}$ ion is greatly improved at the electrolyte/electrode interface ${ }^{55,56}$. To further demonstrate the broader impacts of the proposed concept in the battery field, we electrodeposited 3D Zn-Cu alloy (Supplementary Fig. 44), which could be another materials for high-performance aqueous batteries. Note that the $3 \mathrm{D} \mathrm{Zn}-\mathrm{Cu}$ anode is identified here as a potential extension of the proposed strategy for anode stabilization. We will fully discuss the battery performance of the $\mathrm{Zn}-\mathrm{Cu}$ anode in our future work.

To understand the reaction mechanism and confirm the structural changes of the electrodes during the charge/discharge processes for ZIBs $\left(\mathrm{Zn}_{3} \mathrm{Mn}\right)$, we performed ex-situ X-ray absorption spectroscopy (XAS) measurements ${ }^{53,57,58}$ on the $\mathrm{Zn}$ $\mathrm{Mn}$ anodes and $\mathrm{MnO}_{2}$ cathodes at pristine, fully charged, and fully discharged states. For $\mathrm{MnO}_{2}$ cathodes, we tested the intercalation behaviors of $\mathrm{Zn}-\mathrm{Mn} / \mathrm{MnO}_{2}$, which existed in the seawater-based electrolyte, by using the $\mathrm{Mg}^{2+}$-containing electrolyte. X-ray absorption near edge structure (XANES, Supplementary Fig. 45) on $\mathrm{MnO}_{2}$ cathode shows distinct edge shifts. At the fully discharged state for $\mathrm{MnO}_{2}$ cathode, the XANES spectrum at $\mathrm{Mn}$ K-edge moves to the lower energy compared to that of the pristine $\mathrm{MnO}_{2}$ cathode, suggesting the lower oxidation state of $\mathrm{Mn}$ and the successful intercalation of heteroions in the bulk structure. Furthermore, XANES of charged 

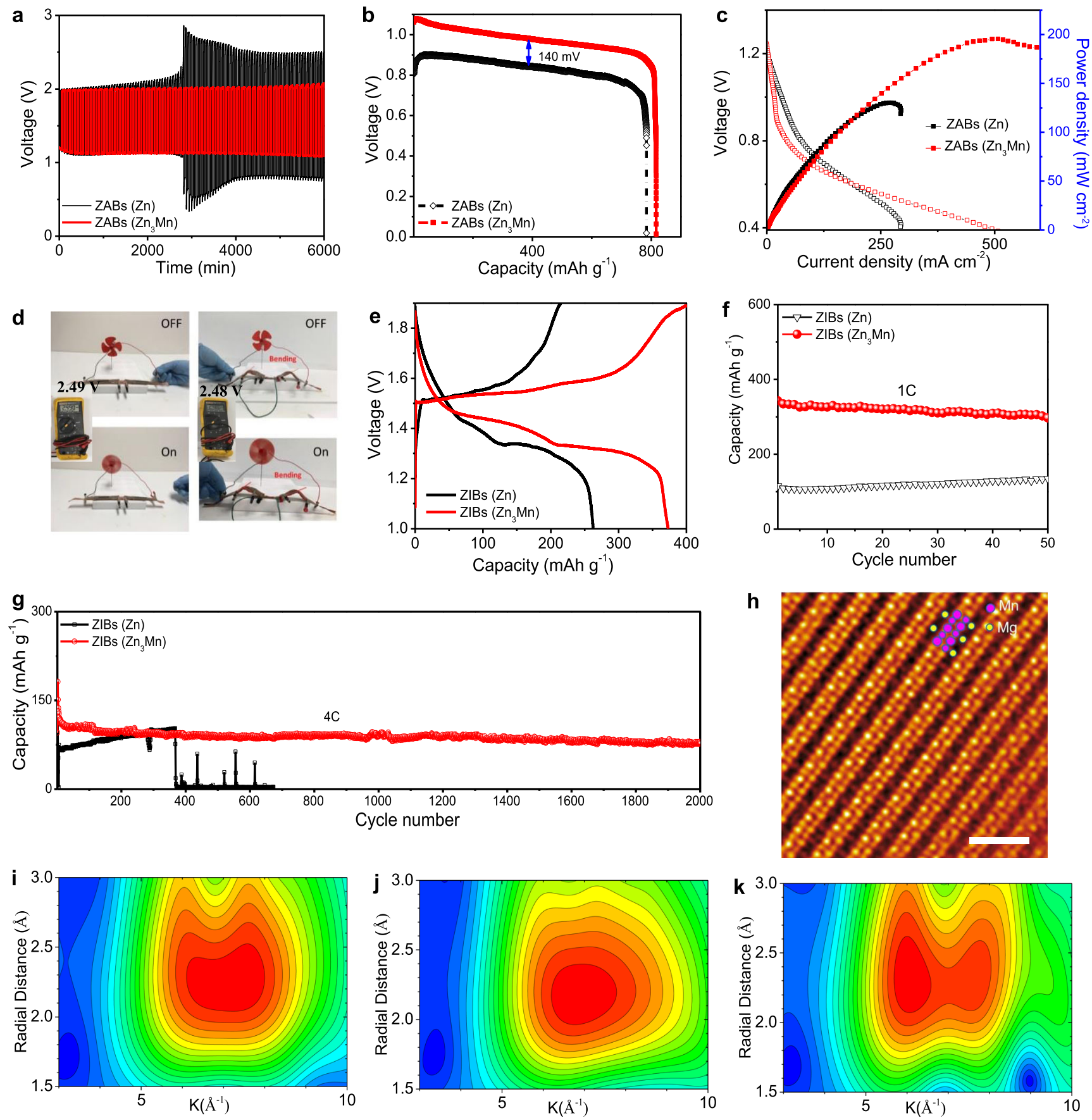

Fig. 4 Electrochemical performance and characterizations of aqueous $\mathbf{Z n}$ batteries. a Cycling performance of $Z A B s\left(Z n_{3} M n\right)$ and $Z A B s(Z n)$. b Discharging plateaus of $Z A B s\left(Z n_{3} M n\right)$ and $Z A B s(Z n)$ at a current density of $30 \mathrm{~mA} \mathrm{~cm}^{-2}$. c Discharging and power density plots of $Z A B s\left(Z n_{3} M n\right)$ and $Z A B s(Z n)$. d Photograph of an electric fan powered by two flexible $Z A B s\left(Z n_{3} M n\right)$. e Typical charge/discharge profiles of $Z I B s ~\left(Z n_{3} M n\right)$ at $0.5 C$ (electrolyte: $2 \mathrm{M} \mathrm{ZnSO}_{4}$ and $0.1 \mathrm{M} \mathrm{MnSO}_{4}$ in seawater). Cycling performance of $\mathrm{ZIBs}\left(\mathrm{Zn}_{3} \mathrm{Mn}\right.$ ) at $\mathbf{f} 1 \mathrm{C}$ and $\mathbf{g} 4 \mathrm{C}$, respectively. $\mathbf{h}$ High-resolution HAADFSTEM image of a fully discharged $\mathrm{MnO}_{2}$ cathode for $\mathrm{ZIBs}\left(\mathrm{Zn}_{3} \mathrm{Mn}\right)$ using $\mathrm{Mg}^{2+}$-containing aqueous electrolyte. The yellow and pink dots represent $\mathrm{Mg}$ and $\mathrm{Mn}$ atoms, respectively. Scale bar: $1 \mathrm{~nm}$. Wavelet transform of Mn K-edge EXAFS for $\mathbf{i}$ pristine $\mathrm{Zn}-\mathrm{Mn}$ anode, $\mathbf{j}$ fully discharged $\mathrm{Zn}-\mathrm{Mn}$ anode, and $\mathbf{k}$ fully charged $\mathrm{Zn}-\mathrm{Mn}$ anode.

$\mathrm{MnO}_{2}$ cathode overlaps with the pristine one, implying good reversibility during charge/discharge processes. We also performed the HAADF-STEM analysis for the fully discharged $\mathrm{MnO}_{2}$ cathode, as shown in Supplementary Fig. 46. The low magnification image (Supplementary Fig. 46a) shows that the $\mathrm{MnO}_{2}$ nanowire maintained a good structure with a smooth surface, indicating the stability of the $\mathrm{MnO}_{2}$ cathode during the charge/discharge process. From the atomic resolution HAADF-
STEM images (Fig. 4h and Supplementary Fig. 46b), $\mathrm{Mg}^{2+}$ insertion was observed in the structure of $\mathrm{MnO}_{2}$. These spectroscopic and microscopic characterizations suggested a completely reversible storage capability of hetero-ions (e.g. $\mathrm{Mg}^{2+}$ ) in $\mathrm{MnO}_{2}$ cathodes of ZIBs $\left(\mathrm{Zn}_{3} \mathrm{Mn}\right)$. The ex-situ XPS spectra of the cycled $\mathrm{Zn}-\mathrm{Mn}$ alloy-based electrodes in $\mathrm{Mg}$ - and $\mathrm{Na}$ containing seawater-based electrolytes were characterized as shown in Supplementary Fig. 47. XPS spectra demonstrate that 
the existence of the adsorption and/or binding of Mn with cations/metal ${ }^{59,60}$. To further confirm the local structure change on the $\mathrm{Zn}$-Mn anode during charge/discharge processes, the onedimensional (1D) Fourier transform of the extended X-ray absorption fine structure (EXAFS) spectra of Mn K-edge for the $\mathrm{Zn}-\mathrm{Mn}$ anode at three states of charge/discharge process (Supplementary Fig. 48) was first applied. Although some changes are found, this 1D EXAFS does not have a good resolution to distinguish the broad peak $\sim 2.2 \AA^{61,62}$. Then the two-dimensional (2D) wavelet transform of the EXAFS spectra was used, as shown in Fig. 4i-k ${ }^{58}$. Clearly, the 2D spectra that combine the $\mathrm{R}$-space and the $\mathrm{k}$-space can distinguish the differences in three states. The single peak found in pristine (Fig. 4i) and fully discharged (Fig. 4j) Zn-Mn anode suggests the existence of Mn-Mn scattering only. In contrast, the fully charged (Fig. 4k) $\mathrm{Zn}-\mathrm{Mn}$ anode has two well-splitting peaks, suggesting the co-existence of $\mathrm{Mn}-\mathrm{Mn}$ and newly formed $\mathrm{Mn}-\mathrm{X}(\mathrm{X}=\mathrm{Mg}$, etc.) scattering that could be due to the adsorption and/or alloying of Mn with cations/metal. All these characterizations confirmed the success of the rationally designed $\mathrm{Zn}-\mathrm{Mn}$ alloy anode and the benefits of using seawater-based electrolytes for aqueous $\mathrm{Zn}$ batteries.

\section{Discussion}

In conclusion, we report a universal strategy for designing $3 \mathrm{D} \mathrm{Zn-}$ $\mathrm{Mn}$ alloy anodes with a potential extension to other alloy-based anode materials for stable, high-performance, dendrite-free, seawater-based aqueous batteries. Equally important, we built an in-situ protocol to mimic the actual electrochemical environments of aqueous batteries and directly observe the metal plating/ stripping processes on the electrode surface. The $3 \mathrm{D} \mathrm{Zn-Mn}$ alloy anode, even under harsh electrochemical environments (heteroions interference from the seawater-based electrolyte and high current density of $80 \mathrm{~mA} \mathrm{~cm}^{-2}$ ), maintained controllable $\mathrm{Zn}$ plating/stripping with robust structural stability and absolute reversibility for aqueous batteries. As a proof-of-concept, the seawater-based aqueous $\mathrm{ZIBs}$ and ZABs using $\mathrm{Zn}-\mathrm{Mn}$ alloy anodes delivered outstanding performance towards energy storage, which proved the novelty and significance of this work. The concept demonstrated in this work will bring a paradigm shift in the design of high-performance alloy anodes for aqueous/nonaqueous batteries and beyond, therefore, revolutionizing the battery industries.

\section{Methods}

Galvanostatic alloy electrodeposition of Zn-Mn alloys. All three-dimensional (3D) structured $\mathrm{Zn}-\mathrm{Mn}$ alloys were electrodeposited on $\mathrm{Zn}$ substrates $(99.95 \%$ metals basis, $0.25 \mathrm{~mm}$ thick, Alfa Aesar ${ }^{\mathrm{TM}}$ ). In all, $100 \mathrm{~mL}$ deionized (DI) water was pre-heated at $80^{\circ} \mathrm{C}$ as the solvent to dissolve $0.2 \mathrm{M}$ zinc sulfate heptahydrate $\left(\mathrm{ZnSO}_{4} \cdot 7 \mathrm{H}_{2} \mathrm{O}\right.$, Fisher Chemical), $0.2 \mathrm{M}$ sodium citrate dihydrate (Granular/Certified), and $0.6 \mathrm{M}$ ethylenediaminetetraacetic acid disodium salt dihydrate (Crystalline/Certified ACS, Fisher Chemical) under continuous stirring for $30 \mathrm{~min}$ (noted as Solution A). Then, $0.6 \mathrm{M}$ manganese (II) sulfate monohydrate $\left(\mathrm{MnSO}_{4} \cdot \mathrm{H}_{2} \mathrm{O}, 99+\%\right.$, extra pure, ACROS Organics ${ }^{\mathrm{TM}}$ ) was added to Solution A and stirred for another $30 \mathrm{~min}$ until a transparent solution was obtained (noted as Solution B). The $\mathrm{Zn}-\mathrm{Mn}$ alloys were then deposited on $\mathrm{Zn}$ substrates using a twoelectrode setup with platinum mesh as the counter electrode at a current density of $0.3 \mathrm{~A} \mathrm{~cm}^{-2}$ in Solution B.

Potentiostatic alloy electrodeposition of $\mathbf{Z n}$-Cu alloys. In total, $100 \mathrm{~mL}$ DI water was pre-heated as the solvent to dissolve zinc sulfate heptahydrate $\left(\mathrm{ZnSO}_{4} \cdot 7 \mathrm{H}_{2} \mathrm{O}\right.$, Fisher Chemical), copper (II) sulfate pentahydrate (Fisher Chemical), and boric acid (Powder/Certified ACS, Fisher Chemical) under continuous stirring for 20 min until a transparent solution was obtained (noted as Solution $\mathrm{C}$ ). The $\mathrm{Zn}-\mathrm{Cu}$ alloys were deposited on $\mathrm{Zn}$ substrates using the two-electrode setup in Solution C.

Zn@Zn anode fabrication. The Zn@Zn anode was electrodeposited in Solution A using the same conditions as those for the deposition of $\mathrm{Zn}-\mathrm{Mn}$ alloy.
Seawater-based aqueous electrolytes. Nine kinds of aqueous electrolytes were prepared: Electrolyte $1\left(2 \mathrm{M} \mathrm{ZnSO}_{4}\right.$ and $0.1 \mathrm{M} \mathrm{MnSO}_{4}$ in DI water); Electrolyte 2 ( $2 \mathrm{M} \mathrm{ZnSO}_{4}$ in DI water); Electrolyte $3\left(2 \mathrm{M} \mathrm{ZnSO}_{4}\right.$ and $0.1 \mathrm{M} \mathrm{MnSO}_{4}$ in seawater); Electrolyte 4 (2 $\mathrm{M} \mathrm{ZnSO}_{4}$ in seawater); Electrolyte $5\left(1 \mathrm{M} \mathrm{ZnSO}_{4}\right.$ and $1 \mathrm{M} \mathrm{MgSO}_{4}$ in seawater); Electrolyte $6\left(1 \mathrm{M} \mathrm{ZnSO}_{4}\right.$ and $1 \mathrm{M} \mathrm{MgSO}_{4}$ in DI water); Electrolyte 7 ( $2 \mathrm{M} \mathrm{MgSO}_{4}$ in seawater); Electrolyte 8 ( $2 \mathrm{M} \mathrm{Na}_{2} \mathrm{SO}_{4}$ in seawater); and Electrolyte 9 ( $2 \mathrm{M} \mathrm{MgSO}_{4}$ in DI water). The seawater was taken from Florida's nearshore zone, physically filtered to remove the suspended particles, and directly used in this work without any other treatment.

Cathode preparation for rechargeable $\mathrm{Zn}$ aqueous batteries. $\mathrm{MnO}_{2}$ cathode materials were prepared for $\mathrm{Zn}$-ion batteries (ZIBs) full-cell testing by a hydrothermal method. Typically, $0.5 \mathrm{~g} \mathrm{MnSO}_{4} \cdot \mathrm{H}_{2} \mathrm{O}$ and $2 \mathrm{~mL} 0.5 \mathrm{M} \mathrm{H}_{2} \mathrm{SO}_{4}$ were added to $100 \mathrm{~mL}$ DI water under continuous stirring until a clear solution (noted as Solution D) was obtained. After that, $25 \mathrm{~mL} 0.1 \mathrm{M} \mathrm{KMnO}_{4}$ aqueous solution was slowly added to Solution D and stirred for $5 \mathrm{~h}$. The as-prepared solution was transferred to a Teflon-lined PTFE autoclave vessel and heated at $120^{\circ} \mathrm{C}$ for $8 \mathrm{~h}$. Then, $\mathrm{MnO}_{2}$ powder was collected, washed by DI water, and dried at $60^{\circ} \mathrm{C}$ overnight in a vacuum oven. The ZIBs cathodes were prepared by a doctor-blade method. First, $\mathrm{MnO}_{2}$ powder, polyvinylidene fluoride (PVDF) binder, and super $\mathrm{P}$ carbon were mixed in N-methyl pyrrolidinone (NMP) solvent in a weight ratio of 7:1:2 to get a homogenous slurry. Then, the obtained mixed slurry was coated onto carbon paper $(\mathrm{CP})$ and dried at $80^{\circ} \mathrm{C}$ overnight in the vacuum oven.

$\mathrm{Pt} / \mathrm{C} @ \mathrm{RuO}_{2}$ and F-doped PtCo nanosheets on the nickel foam (PtCoF@nickel foam) were prepared as cathodes for $\mathrm{Zn}$-air batteries (ZABs) testing according to our prior work ${ }^{53}$. The $\mathrm{Pt} / \mathrm{C} @ \mathrm{RuO}_{2}$ cathode was prepared in the following procedure: (1) $3.2 \mathrm{mg} \mathrm{Pt} / \mathrm{C}$ powder was mixed with $3.2 \mathrm{mg} \mathrm{RuO}_{2}$ in the $3.2-\mathrm{ml}$ Nafion/isopropanol solution $(98: 2, \mathrm{v} / \mathrm{v})$, and then ultrasonicated for $20 \mathrm{~min}$. The obtained suspension was disposed on $4 \times 4 \mathrm{~cm}^{2}$ carbon paper and dried at $60^{\circ} \mathrm{C}$. The single-atom PtCoF@nickel foam was prepared by fluorine (F)-plasma treatment using carbon tetrafluoride as a source in a plasma etcher (Trion MiniLock II RIE-ICP) using the PtCo@nickel foam as a precursor.

Electrochemical tests. Symmetric cells were assembled using $\mathrm{Zn}$ (or $\mathrm{Zn}-\mathrm{Mn}$ alloy) foils as both cathode and anode, which were separated by a glass fiber membrane saturated with different aqueous electrolytes. For $\mathrm{Cu} / / \mathrm{Zn}$ (or $\mathrm{Cu} / / \mathrm{Zn}-\mathrm{Mn}$ ) cells, $\mathrm{Cu}$ and $\mathrm{Zn}$ (or $\mathrm{Zn}-\mathrm{Mn}$ alloy) foils were used as cathode and anode, respectively, for the plating/stripping tests in the aqueous $\mathrm{Zn}$ batteries. The active areas of electrodes were $1 \mathrm{~cm}^{2}(1 \mathrm{~cm} \times 1 \mathrm{~cm})$ in coin cells. Cyclic voltammetry $(\mathrm{CV})$ and electrochemical impedance spectroscopy (EIS) data were measured by $\mathrm{CHI} 600 \mathrm{E}$ electrochemical workstation. The electrochemical performance of aqueous electrolytes was tested in a three-electrode setup (Pt mesh as the working electrode, $\mathrm{Zn}$ (or $\mathrm{Zn}$ $\mathrm{Mn}$ alloy) foil as both counter and reference electrodes) at a scan rate of $1 \mathrm{mV} \mathrm{s}^{-1}$

$\mathrm{Zn}$ (or $\mathrm{Zn}-\mathrm{Mn}$ alloy) anodes and $\mathrm{MnO}_{2} @$ Carbon Paper $\left(\mathrm{MnO}_{2} @ \mathrm{CP}\right)$ cathodes were assembled in CR2032 coin cells for the ZIBs full-cell testing. The mass loading of $\mathrm{MnO}_{2}$ was 2-3 mg cm ${ }^{-2}$. Pt/C@ $\mathrm{RuO}_{2}$ (or PtCoF@nickel foam) cathodes and $\mathrm{Zn}$ ( $\mathrm{Zn}-\mathrm{Mn}$ alloy) anodes were assembled with an electrolyte consisting of $6 \mathrm{M} \mathrm{KOH}$ and $0.2 \mathrm{M}$ zinc acetate for ZABs full-cell testing. Gel electrolytes were also prepared by mixing polyvinyl alcohol (PVA) powder with $6 \mathrm{M} \mathrm{KOH}$ and $0.2 \mathrm{M}$ zinc acetate at $80^{\circ} \mathrm{C}$ to assemble the flexible ZABs.

Materials characterizations. X-ray diffraction patterns (XRD) were obtained on a film XRD system (Panalytical X'celerator multi-element detector with $\mathrm{Cu} \mathrm{Ka}$ radiation source, $\lambda=1.54056 \AA$ ). The surface topographies were characterized by atomic force microscopy (AFM, Veeco Dimension 3100) using tapping mode. The contact angles were measured with an OCA 15EC goniometer and analyzed with the SCA 20 module from DataPhysics Instruments. A droplet volume of $3 \mu \mathrm{L}$ was used for each measurement. The morphologies of the materials were characterized by scanning electron microscopy (SEM, ZEISS ultra 55) with EDS mapping. Transmission electron microscopy (TEM), high angle annular dark-field scanning transmission electron microscopy (HAADF-STEM), and X-ray spectroscopy (EDS) were performed using a probe corrected FEI Titan 80-300 microscope operating at $300 \mathrm{kV}$. Mn K-edge X-ray absorption spectroscopy experiments were carried out at beamline 12BM, Advanced Photon Source (APS), Argonne National Laboratory (ANL). Data reduction, data analysis, and EXAFS fitting were performed with the Athena, Artemis, and IFEFFIT software packages.

In-situ optical imaging. To realize in-situ imaging of $\mathrm{Zn}$ plating/stripping dynamics, a two-electrode system was used in which the pristine $\mathrm{Zn}$ foils were employed as counter and reference electrodes, and 3D Zn-Mn alloy was used as a working electrode. To realize the in-situ imaging in the aqueous electrolyte, a special electrochemical cell was designed using polydimethylsiloxane (PDMS, prepared by the mixing of base elastomer and curing agent with a ratio of 10:1 and then cross-linking for $3 \mathrm{~h}$ at $75^{\circ} \mathrm{C}$ ) to hold the electrolyte. In all, $800 \mu \mathrm{L}$ electrolyte was applied to the cell with a size of $1 \mathrm{~cm} \times 1 \mathrm{~cm} \times 3 \mathrm{~mm}$. Images were recorded with a CCD camera (FLIR Blackfly S USB 3, $720 \times 540$ pixels) on an Olympus BX60 upright microscope. To minimize the refractive index mismatch between the air and high concentration saline electrolyte, a $\times 20$ water immersion objective (working distance: $2 \mathrm{~mm}$, N.A. 1.0, Thorlab) was submerged into the electrolytes 
and the reflected images of the electrode surface were obtained. The setup diagram is shown in Fig. 3a. The imaging area was $200-400 \mu \mathrm{m}$ away from the top electrode's projection. Different current densities $\left(5-80 \mathrm{~mA} \mathrm{~cm}^{-2}\right)$ were applied, and four electrolytes (Electrolyte 1: $2 \mathrm{M} \mathrm{ZnSO}_{4}$ in seawater; Electrolyte 2: $2 \mathrm{M} \mathrm{ZnSO}_{4}$ with $0.1 \mathrm{M} \mathrm{MnSO}_{4}$ in seawater; Electrolyte $3: 2 \mathrm{M} \mathrm{ZnSO}_{4}$ with $0.1 \mathrm{M} \mathrm{MnSO}_{4}$ in DI water; Electrolyte 4: $2 \mathrm{M} \mathrm{ZnSO}_{4}$ in DI water) were tested to investigate the $\mathrm{Zn}$ plating process. To compare with the $3 \mathrm{D} \mathrm{Zn}-\mathrm{Mn}$ alloy, a pristine $\mathrm{Zn}$ foil anode was also tested in Electrolyte 2. After the $\mathrm{Zn}$ plating, the current density of $80 \mathrm{~mA} \mathrm{~cm}{ }^{-2}$ was used to analyze the stripping process of the $3 \mathrm{D} \mathrm{Zn}-\mathrm{Mn}$ anode.

DFT calculations. Density functional theory (DFT) simulation was conducted to analyze the adsorption and kinetics of $\mathrm{Zn}$ ad-atoms on the experimentally confirmed $\mathrm{Zn}_{3} \mathrm{Mn}$ (110) surface. For the simplicity and the efficiency of the calculation, the simulation was conducted on the cubic cell to extract the effect of Mn substitution alone. The simulation model was constructed with $40 \mathrm{Zn}$ and $16 \mathrm{Mn}$ atoms in a unit cell of $1.08 \times 0.76 \times 2.08 \mathrm{~nm}$. The $x, y$, and $z$ directions of the cell correspond to [001], [1-10], and [110] crystal orientation, respectively. A vacuum layer of $1.2 \mathrm{~nm}$ was included in the $z$-direction to avoid the interaction from the neighboring cells in a periodic boundary condition. Vienna Ab-initio Simulation Package (VASP) was used in the calculation ${ }^{63,64}$, with projector augmented wave (PAW) pseudopotential ${ }^{65,66}$ and generalized gradient approximation by PerdewBurke-Ernzerhof ${ }^{67}$. The plane wave energy cut off was $400 \mathrm{eV}$ and

$3 \times 5 \times 1 k$-points were selected based on the Monkhorst-Pack method ${ }^{68}$. First, the conjugate gradient structure optimization was performed while fixing the atoms in the bottom two layers. Then, a $\mathrm{Zn}$ atom was placed on the surface at $10 \times 10$ grid points and structural optimization was performed. Here only the ad-atom was relaxed in $z$-direction while fixing the $x$ and y coordinates. Also, a $\mathrm{Zn}$ ad-atom was placed on a surface lattice point and structure optimization was conducted to calculate the binding energy. The binding energy calculation was also performed on the $\mathrm{Zn}$ (110) surface for comparison. The binding energies were calculated by the (total energy of the system w/o $\mathrm{Zn}$ ad-atom) + (isolated $\mathrm{Zn}$ atom) - (total energy of the model $\mathrm{w} / \mathrm{Zn}$ ad-atom).

\section{Data availability}

The data that support the findings of this study are available from the corresponding author upon reasonable request.

Received: 9 October 2020; Accepted: 26 November 2020;

Published online: 11 January 2021

\section{References}

1. Armand, M. \& Tarascon, J. M. Building better batteries. Nature 451, 652-657 (2008).

2. Pan, H. L. et al. Reversible aqueous zinc/manganese oxide energy storage from conversion reactions. Nat. Energy 1, 16039 (2016).

3. Tang, B. Y., Shan, L. T., Liang, S. Q. \& Zhou, J. Issues and opportunities facing aqueous zinc-ion batteries. Energy Environ. Sci. 12, 3288-3304 (2019).

4. Higashi, S., Lee, S. W., Lee, J. S., Takechi, K. \& Cui, Y. Avoiding short circuits from zinc metal dendrites in anode by backside-plating configuration. Nat. Commun. 7, 11801 (2016).

5. Deng, Y.-P. et al. The current state of aqueous $\mathrm{Zn}$-based rechargeable batteries. ACS Energy Lett. 5, 1665-1675 (2020).

6. Hopkins, B. J., Shao-Horn, Y. \& Hart, D. P. Suppressing corrosion in primary aluminum-air batteries via oil displacement. Science 362, 658-661 (2018).

7. Li, C.-S., Sun, Y., Gebert, F. \& Chou, S.-L. Current progress on rechargeable magnesium-air battery. Adv. Energy Mater. 7, 1700869 (2017).

8. Li, Y. \& Lu, J. Metal-air batteries: will they be the future electrochemical energy storage device of choice? ACS Energy Lett. 2, 1370-1377 (2017).

9. Lu, Y. Y., Tu, Z. Y. \& Archer, L. A. Stable lithium electrodeposition in liquid and nanoporous solid electrolytes. Nat. Mater. 13, 961-969 (2014).

10. Ma, J. L. et al. Prevention of dendrite growth and volume expansion to give high-performance aprotic bimetallic Li-Na alloy- $\mathrm{O}_{2}$ batteries. Nat. Chem. 11, 64-70 (2019).

11. Wang, F. et al. Highly reversible zinc metal anode for aqueous batteries. Nat. Mater. 17, 543-549 (2018).

12. Davidson, R. et al. Formation of magnesium dendrites during electrodeposition. ACS Energy Lett. 4, 375-376 (2019).

13. Xiao, N., McCulloch, W. D. \& Wu, Y. Reversible dendrite-free potassium plating and stripping electrochemistry for potassium secondary batteries. $J$. Am. Chem. Soc. 139, 9475-9478 (2017).

14. Li, Y. Z. et al. Atomic structure of sensitive battery materials and Interfaces revealed by cryo-electron microscopy. Science 358, 506-510 (2017).

15. Zhu, M. Q. et al. Homogeneous guiding deposition of sodium through main group II metals toward dendrite-free sodium anodes. Sci. Adv. 5, eaau6264 (2019).
16. Zheng, J. X. et al. Reversible epitaxial electrodeposition of metals in battery anodes. Science 366, 645-648 (2019).

17. Parker, J. F. et al. Rechargeable nickel-3D zinc batteries: an energy-dense, safer alternative to lithium-ion. Science 356, 415 (2017).

18. Kang, L. et al. Nanoporous $\mathrm{CaCO}_{3}$ coatings enabled uniform $\mathrm{Zn}$ stripping/ plating for long-life zinc rechargeable aqueous batteries. Adv. Energy Mater. 8 1801090 (2018).

19. Choudhury, S. et al. Designing solid-liquid interphases for sodium batteries. Nat. Commun. 8, 898 (2017).

20. Zhang, X. Y., Wang, A. X., Liu, X. J. \& Luo, J. Y. Dendrites in lithium metal anodes: suppression, regulation, and elimination. Acc. Chem. Res. 52, 3223-3232 (2019).

21. Suo, L. et al. "Water-in-salt" electrolyte enables high-voltage aqueous lithiumion chemistries. Science 350, 938 (2015)

22. Suo, L. et al. Advanced high-voltage aqueous lithium-ion battery enabled by "water-in-bisalt" electrolyte. Angew. Chem. Int. Ed. 55, 7136-7141 (2016).

23. Yang, C. et al. Aqueous Li-ion battery enabled by halogen conversion-intercalation chemistry in graphite. Nature 569, 245-250 (2019).

24. Yan, J. et al. Rechargeable hybrid aqueous batteries. J. Power Sources 216, 222-226 (2012).

25. Yamada, Y. et al. Hydrate-melt electrolytes for high-energy-density aqueous batteries. Nat. Energy 1, 16129 (2016).

26. Ye, H. et al. Guiding uniform Li plating/stripping through lithium-aluminum alloying medium for long-life Li metal batteries. Angew. Chem. Int. Ed. 58, 1094-1099 (2019)

27. Kong, L.-L. et al. Lithium-magnesium alloy as a stable anode for lithium-sulfur battery. Adv. Funct. Mater. 29, 1808756 (2019).

28. Ding, F. et al. Dendrite-free lithium deposition via self-healing electrostatic shield mechanism. J. Am. Chem. Soc. 135, 4450-4456 (2013).

29. Chen, P.-Y. \& Hussey, C. L. The electrodeposition of Mn and $\mathrm{Zn}-\mathrm{Mn}$ alloys from the room-temperature tri-1-butylmethylammonium bis ((trifluoromethane)sulfonyl)imide ionic liquid. Electrochim. Acta 52, 1857-1864 (2007).

30. Jaber, A. Y., Alamri, S. N. \& Aida, M. S. CdS thin films growth by ammonia free chemical bath deposition technique. Thin Solid Films 520, 3485-3489 (2012).

31. Costovici, S., Manea, A.-C., Visan, T. \& Anicai, L. Investigation of Ni-Mo and Co-Mo alloys electrodeposition involving choline chloride based ionic liquids. Electrochim. Acta 207, 97-111 (2016).

32. Wang, H. et al. Engineering $\mathrm{Fe}-\mathrm{Fe}_{3} \mathrm{C} @ \mathrm{Fe}-\mathrm{N}-\mathrm{C}$ active sites and hybrid structures from dual metal-organic frameworks for oxygen reduction reaction in $\mathrm{H}_{2}-\mathrm{O}_{2}$ fuel cell and Li-O $\mathrm{O}_{2}$ battery. Adv. Funct. Mater. 29, 1901531 (2019).

33. Shi, Y. et al. A tunable 3D nanostructured conductive gel framework electrode for high-performance lithium ion batteries. Adv. Mater. 29, 1603922 (2017).

34. Yuksel, R., Buyukcakir, O., Seong, W. K. \& Ruoff, R. S. Metal-organic framework integrated anodes for aqueous zinc-ion batteries. Adv. Energy Mater. 10, 1904215 (2020).

35. Uthaisar, C. \& Barone, V. Edge effects on the characteristics of Li diffusion in graphene. Nano Lett. 10, 2838-2842 (2010).

36. Persson, K., Hinuma, Y., Meng, Y. S., Van der Ven, A. \& Ceder, G. Thermodynamic and kinetic properties of the Li-graphite system from firstprinciples calculations. Phys. Rev. B 82, 125416 (2010).

37. Mandeltort, L. \& Yates, J. T. Rapid atomic Li surface diffusion and intercalation on graphite: a surface science study. J. Phys. Chem. C 116, 24962-24967 (2012)

38. Politano, A. et al. Photothermal membrane distillation for seawater desalination. Adv. Mater. 29, 1603504 (2017).

39. Fridman-Bishop, N., Nir, O., Lahav, O. \& Freger, V. Predicting the rejection of major seawater ions by spiral-wound nanofiltration membranes. Environ. Sci. Technol. 49, 8631-8638 (2015).

40. $\mathrm{Bi}, \mathrm{H}$. et al. A universal approach to aqueous energy storage via ultralow-cost electrolyte with super-concentrated sugar as hydrogen-bond-regulated solute. Adv. Mater. 32, 2000074 (2020).

41. Fashu, S. et al. Electrodeposition, morphology, composition, and corrosion performance of $\mathrm{Zn}-\mathrm{Mn}$ coatings from a deep eutectic solvent. J. Mater. Eng. 24, 434-444 (2015).

42. Xie, X. et al. Manipulating the ion-transfer kinetics and interface stability for high-performance zinc metal anodes. Energy Environ. Sci. 13, 503-510 (2020).

43. Pei, A., Zheng, G., Shi, F., Li, Y. \& Cui, Y. Nanoscale nucleation and growth of electrodeposited lithium metal. Nano Lett. 17, 1132-1139 (2017).

44. Lin, C.-H. et al. Systems-level investigation of aqueous batteries for understanding the benefit of water-in-salt electrolyte by synchrotron nanoimaging. Sci. Adv. 6, eaay7129 (2020).

45. Lee, D. U., Choi, J.-Y., Feng, K., Park, H. W. \& Chen, Z. Advanced extremely durable 3D bifunctional air electrodes for rechargeable zinc-air batteries. $A d v$ Energy Mater. 4, 1301389 (2014).

46. Xiao, W. P. et al. Atomic rearrangement from disordered to ordered Pd-Fe nanocatalysts with trace amount of Pt decoration for efficient electrocatalysis. Nano Energy 50, 70-78 (2018). 
47. Zhao, Z. Q. et al. Challenges in zinc electrodes for alkaline zinc-air batteries: obstacles to commercialization. ACS Energy Lett. 4, 2259-2270 (2019).

48. Li, Y. G. \& Dai, H. J. Recent advances in zinc-air batteries. Chem. Soc. Rev. 43, 5257-5275 (2014)

49. Ji, D. et al. The kirkendall effect for engineering oxygen vacancy of hollow $\mathrm{Co}_{3} \mathrm{O}_{4}$ nanoparticles toward high-performance portable zinc-air batteries. Angew. Chem. Int. Ed. 58, 13840-13844 (2019).

50. Lu, X. F., Chen, Y., Wang, S., Gao, S. \& Lou, X. W. Interfacing manganese oxide and cobalt in porous graphitic carbon polyhedrons boosts oxygen electrocatalysis for Zn-Air batteries. Adv. Mater. 31, 1902339 (2019).

51. Han, X. et al. Generation of nanoparticle, atomic-cluster, and single-atom cobalt catalysts from zeolitic imidazole frameworks by spatial isolation and their use in zinc-air batteries. Angew. Chem. Int. Ed. 58, 5359-5364 (2019).

52. Zhou, T., Zhang, N., Wu, C. \& Xie, Y. Surface/interface nanoengineering for rechargeable Zn-air batteries. Energy Environ. Sci. 13, 1132-1153 (2020).

53. Li, Z. et al. Stabilizing atomic Pt with trapped interstitial F in alloyed PtCo nanosheets for high-performance zinc-air batteries. Energy Environ. Sci. 13, 884-895 (2020).

54. Chamoun, M., Brant, W. R., Tai, C.-W., Karlsson, G. \& Noréus, D. Rechargeability of aqueous sulfate $\mathrm{Zn} / \mathrm{MnO}_{2}$ batteries enhanced by accessible $\mathrm{Mn}^{2+}$ ions. Energy Storage Mater. 15, 351-360 (2018).

55. Sun, W. et al. $\mathrm{Zn} / \mathrm{MnO}_{2}$ battery chemistry with $\mathrm{H}^{+}$and $\mathrm{Zn}^{2+}$ coinsertion. J. Am. Chem. Soc. 139, 9775-9778 (2017).

56. Chen, L. et al. Graphene-wrapped hollow $\mathrm{ZnMn}_{2} \mathrm{O}_{4}$ microspheres for highperformance cathode materials of aqueous zinc ion batteries. Electrochim. Acta 317, 155-163 (2019).

57. Ju, L. et al. Significantly improved cyclability of conversion-type transition metal oxyfluoride cathodes by homologous passivation layer reconstruction. Adv. Energy Mater. 10, 1903333 (2020).

58. Wang, M., Árnadóttir, L., Xu, Z. J. \& Feng, Z. In situ X-ray absorption spectroscopy studies of nanoscale electrocatalysts. Nano-Micro Lett. 11, 47 (2019).

59. He, W., Zhang, E. \& Yang, K. Effect of $\mathrm{Y}$ on the bio-corrosion behavior of extruded Mg-Zn-Mn alloy in Hank's solution. Mater. Sci. Eng. C 30, 167-174 (2010).

60. Kurra, S. et al. Enhancement of photocatalytic activity of sodium bismuth titanate by doping with copper, silver, and tin ions. Z. Anorg. Allg. Chem. 645, 529-536 (2019).

61. Funke, H., Scheinost, A. C. \& Chukalina, M. Wavelet analysis of extended $\mathrm{x}$ ray absorption fine structure data. Phys. Rev. B 71, 094110 (2005).

62. Li, P. et al. Boosting oxygen evolution of single-atomic ruthenium through electronic coupling with cobalt-iron layered double hydroxides. Nat. Commun. 10, 1711 (2019).

63. Kresse, G. \& Hafner, J. Ab initio molecular dynamics for liquid metals. Phys. Rev. B 47, 558-561 (1993).

64. Kresse, G. \& Furthmüller, J. Efficient iterative schemes for ab initio totalenergy calculations using a plane-wave basis set. Phys. Rev. B 54, 11169-11186 (1996).

65. Kresse, G. \& Joubert, D. From ultrasoft pseudopotentials to the projector augmented-wave method. Phys. Rev. B 59, 1758-1775 (1999).

66. Blöchl, P. E. Projector augmented-wave method. Phys. Rev. B 50, 17953-17979 (1994).

67. Perdew, J. P., Burke, K. \& Ernzerhof, M. Generalized gradient approximation made simple. Phys. Rev. Lett. 77, 3865-3868 (1996).

68. Monkhorst, H. J. \& Pack, J. D. Special points for Brillouin-zone integrations. Phys. Rev. B 13, 5188-5192 (1976).

\section{Acknowledgements}

This work was primarily supported by the National Science Foundation under grant no CBET-1949840, CMMI-1851674, CBET-1949870, CBET-2016192, and the startup grant from the University of Central Florida (UCF). H.T. thanks for the Preeminent Postdoctoral Program (P3) at UCF. Z.F. thanks for the startup funding from Oregon State University. This research used resources of the beamline 12-BM of the Advanced Photon Source (APS), a U.S. Department of Energy (DOE) Office of Science User Facility operated for the DOE Office of Science by Argonne National Laboratory under Contract DE-AC02-06CH11357. TEM and data analysis were supported by the U.S. Department of Energy, Office of Science, Office of Basic Energy Sciences, and Early Career Research Program under award \#68278. A portion of the research was performed using EMSL, a DOE User Facility sponsored by the Office of Biological and Environmental Research and located at the Pacific Northwest National Laboratory.

\section{Author contributions}

Y.Y. led the team and supervised the experiments. H.T. prepared the materials and performed the electrochemical analyses. Z.L. prepared the materials and performed the $\mathrm{Zn}$-air batteries tests. X.S. and G.F. built the in-situ visualization protocol for the $\mathrm{Zn}$ plating/stripping imaging. H.Z., M.W., and Z.F. performed the XAS analyses. Z.Y. and Y.D. performed the TEM characterizations and data analysis. D.F. and L.Z. carried out the surface wettability and AFM investigations. A.K. conducted the DFT calculations. All authors contributed to the discussion.

\section{Competing interests}

The authors declare no competing interests.

\section{Additional information}

Supplementary information is available for this paper at https://doi.org/10.1038/s41467020-20334-6.

Correspondence and requests for materials should be addressed to Z.F., X.S. or Y.Y.

Peer review information Nature Communications thanks the anonymous reviewers for their contribution to the peer review of this work.

Reprints and permission information is available at http://www.nature.com/reprints

Publisher's note Springer Nature remains neutral with regard to jurisdictional claims in published maps and institutional affiliations.

Open Access This article is licensed under a Creative Commons Attribution 4.0 International License, which permits use, sharing, adaptation, distribution and reproduction in any medium or format, as long as you give appropriate credit to the original author(s) and the source, provide a link to the Creative Commons license, and indicate if changes were made. The images or other third party material in this article are included in the article's Creative Commons license, unless indicated otherwise in a credit line to the material. If material is not included in the article's Creative Commons license and your intended use is not permitted by statutory regulation or exceeds the permitted use, you will need to obtain permission directly from the copyright holder. To view a copy of this license, visit http://creativecommons.org/ licenses/by/4.0/.

(c) The Author(s) 2021 